\title{
Comparative measurements of ambient atmospheric concentrations of ice nucleating particles using multiple immersion freezing methods and a continuous flow diffusion chamber
}

\author{
Paul J. DeMott ${ }^{1}$, Thomas C. J. Hill ${ }^{1}$, Markus D. Petters ${ }^{2}$, Allan K. Bertram ${ }^{3}$, Yutaka Tobo ${ }^{4,5}$, Ryan H. Mason ${ }^{3}$, \\ Kaitlyn J. Suski $^{1}{ }^{1}$, Christina S. McCluskey $^{1}$, Ezra J. T. Levin ${ }^{1}$, Gregory P. Schill ${ }^{1}$, Yvonne Boose $^{6}$, Anne \\ Marie Rauker ${ }^{1}$, Anna J. Miller ${ }^{7}$, Jake Zaragoza ${ }^{1, b}$, Katherine Rocci ${ }^{8}$, Nicholas E. Rothfuss ${ }^{2}$, Hans P. Taylor ${ }^{2}$, \\ John D. Hader ${ }^{2}$, Cedric Chou ${ }^{3}$, J. Alex Huffman ${ }^{9}$, Ulrich Pöschl ${ }^{10}$, Anthony J. Prenni ${ }^{11}$, and Sonia M. Kreidenweis ${ }^{1}$ \\ ${ }^{1}$ Department of Atmospheric Science, Colorado State University, Fort Collins, CO 80523, USA \\ ${ }^{2}$ Department of Marine, Earth and Atmospheric Sciences, North Carolina State University, Raleigh, NC 27695, USA \\ ${ }^{3}$ Department of Chemistry, University of British Columbia, Vancouver, BC, V6T1Z1, Canada \\ ${ }^{4}$ National Institute of Polar Research, Tachikawa, Tokyo 190-8518, Japan \\ ${ }^{5}$ Department of Polar Science, School of Multidisciplinary Sciences, SOKENDAI (The Graduate School for Advanced \\ Studies), Tachikawa, Tokyo 190-8518, Japan \\ ${ }^{6}$ Karlsruhe Institute of Technology, Institute of Meteorology and Climate Research (IMK-IFU), \\ 82467 Garmisch-Partenkirchen, Germany \\ ${ }^{7}$ Department of Chemistry, Reed College, Portland, OR 97202, USA \\ ${ }^{8}$ Department of Earth Sciences, University of New Hampshire, Durham, NH 03824, USA \\ ${ }^{9}$ Department of Chemistry \& Biochemistry, University of Denver, Denver, CO 80210, USA \\ ${ }^{10}$ Department of Multiphase Chemistry, Max Planck Institute for Chemistry, 55128 Mainz, Germany \\ ${ }^{11}$ National Park Service, Air Resources Division, Lakewood, CO 80228, USA \\ anow at: Pacific Northwest National Laboratory, Richland, WA 99352, USA \\ b now at: Air Resource Specialists, Fort Collins, CO 80525, USA
}

Correspondence to: Paul J. DeMott (paul.demott@Colostate.edu)

Received: 3 May 2017 - Discussion started: 8 May 2017

Revised: 15 August 2017 - Accepted: 23 August 2017 - Published: 22 September 2017

\begin{abstract}
A number of new measurement methods for ice nucleating particles (INPs) have been introduced in recent years, and it is important to address how these methods compare. Laboratory comparisons of instruments sampling major INP types are common, but few comparisons have occurred for ambient aerosol measurements exploring the utility, consistency and complementarity of different methods to cover the large dynamic range of INP concentrations that exists in the atmosphere. In this study, we assess the comparability of four offline immersion freezing measurement methods (Colorado State University ice spectrometer, IS; North Carolina State University cold stage, CS; National Institute for Polar Research Cryogenic Refrigerator Applied to Freezing Test, CRAFT; University of British Columbia microorifice uniform deposit impactor-droplet freezing technique,
\end{abstract}

MOUDI-DFT) and an online method (continuous flow diffusion chamber, CFDC) used in a manner deemed to promote/maximize immersion freezing, for the detection of INPs in ambient aerosols at different locations and in different sampling scenarios. We also investigated the comparability of different aerosol collection methods used with offline immersion freezing instruments. Excellent agreement between all methods could be obtained for several cases of co-sampling with perfect temporal overlap. Even for sampling periods that were not fully equivalent, the deviations between atmospheric INP number concentrations measured with different methods were mostly less than 1 order of magnitude. In some cases, however, the deviations were larger and not explicable without sampling and measurement artifacts. Overall, the immersion freezing methods seem to 
effectively capture INPs that activate as single particles in the modestly supercooled temperature regime $\left(>-20^{\circ} \mathrm{C}\right)$, although more comparisons are needed in this temperature regime that is difficult to access with online methods. Relative to the CFDC method, three immersion freezing methods that disperse particles into a bulk liquid (IS, CS, CRAFT) exhibit a positive bias in measured INP number concentrations below $-20^{\circ} \mathrm{C}$, increasing with decreasing temperature. This bias was present but much less pronounced for a method that condenses separate water droplets onto limited numbers of particles prior to cooling and freezing (MOUDI-DFT). Potential reasons for the observed differences are discussed, and further investigations proposed to elucidate the role of all factors involved.

\section{Introduction}

Heterogeneous ice nucleation by atmospheric aerosols impacts the microphysical composition, radiative properties and precipitation processes in clouds colder than $0^{\circ} \mathrm{C}$. These interactions are complex, and any first assessment of the role of different particles on ice formation, cloud properties and climate requires more observations of ice nucleating particles (INPs, as defined by Vali et al., 2015) present in ambient air. To quantify the initial stage of ice nucleation in the atmosphere, multiple sampling techniques are now being used in field studies (Hader et al., 2014; Mason et al., 2015; DeMott et al., 2015; Stopelli et al, 2015; Boose et al., 2016; Schrod et al., 2016, 2017). Since these various measurements are being used as bases for developing numerical model parameterizations for different emission sources, their comparability should be assessed. In this study, we focus on ice nucleation measurements in the mixed-phase cloud temperature regime $\left(0\right.$ to $\left.-38^{\circ} \mathrm{C}\right)$, where heterogeneous ice nucleation is the only trigger for primary ice initiation. Within this regime, INP number concentration can increase up to 10 orders of magnitude as temperatures cool from -5 to $-35^{\circ} \mathrm{C}$ (DeMott et al., 2015, 2016; Hiranuma et al., 2015; Murray et al., 2012; Petters and Wright, 2015), and there can be up to $2-3$ orders of magnitude of temporal and spatial variability at a single temperature by any given method (DeMott et al., 2010; Petters and Wright, 2015).

This study compares results from an online INP measurement method used over the last 25 years, the Colorado State University (CSU) continuous flow diffusion chamber (CFDC), with four offline immersion freezing methods for INP measurements. These four variants immerse particles into variously sized liquid volumes/droplets which are cooled to freezing in different ways in order to measure the immersion freezing INP number per volume of air. In this study, comparisons are made only for times when the CFDC instrument operated in a manner which emphasized immersion freezing contributions to ice nucleation (DeMott et al.,
2015). A principal reason to evaluate consistency between approaches, and in ambient air, is because offline methods collect large enough sample volumes to estimate INP number concentrations active at modest supercooling (as warm as $-5^{\circ} \mathrm{C}$ ), a temperature regime where online instruments are unable to obtain statistically significant data samples. In contrast, online methods can provide high-time-resolution data at lower temperatures. Comparability between off- and online methods can be assessed in temperature regions of overlap. Another reason for such a comparison is to gauge the magnitude of uncertainties when only a single INP measurement method is used or when data sets from different instruments are combined toward addressing a scientific question. This study differs from previous efforts in that comparisons have been restricted to the ambient atmosphere, where presumably the compositions of INPs are more diverse and likely different than for single INP types often examined in laboratory studies. In one set of laboratory studies (Hiranuma et al., 2015), discrepancies between online and offline methods were noted for sampling NX-illite INPs. In particular, bulk, offline freezing methods estimated INP ice nucleation efficiencies that were 10-1000 times lower than found with continuous flow chambers and the AIDA (Aerosol Interaction and Dynamics in the Atmosphere) expansion cloud chamber for temperatures warmer than about $-25^{\circ} \mathrm{C}$. Similar discrepancies were discussed by Emersic et al. (2016). Impacts of dry dispersion vs. wet immersion on the agglomeration properties and the exposures of active sites were implicated in varied ways in both studies for explaining discrepancies. Grawe et al. (2016) also noted discrepancies occurring in single-particle activation via immersion freezing in the LACIS (Leipzig Aerosol Cloud Interaction Simulator) instrument for certain, but not all, combustion ash particles. In contrast, no discrepancies were reported in processing wet-dispersed ice nucleating bacteria from Snomax ${ }^{\circledR}$ (Wex et al., 2014). Nevertheless, many of the reported laboratory results have thus far focused on a specific INP type that was shared across laboratories and for which individual investigators were allowed to determine protocols for generation as an aerosol or production of liquid suspensions for the different methods used. Here, by contrast, we focus on co-located sampling of ambient aerosol, for which no more than two methods have hitherto been used in a single published study using this approach.

The goal of this intercomparison is to assess the status and potential for using single or combinations of INP measurement methods to access and measure the dynamic range of atmospheric INP concentrations active for ice initiation in mixed-phase clouds. The assessment assumes that the time dependence is subordinate to the temperature dependence of the freezing nucleation process. The scientific basis of this assumption and its implications for the assessment are discussed. We address the magnitude of agreement; how particle collection methods may influence immersion freezing measurements; and whether obvious biases appear, for example 
due to the different size ranges of particles that may be collected in offline and online measurement systems. This study is intended not as a comprehensive evaluation but rather as a first assessment using some of the most common methods likely to be applied for atmospheric sampling in the coming years.

\section{Methods}

Several INP measurement methods, most with a legacy of previous atmospheric measurements, are herein intercompared during sampling of ambient aerosols. This section describes the instruments, details of sampling protocol and processing, and sampling sites.

\subsection{INP measurement systems}

\subsubsection{Colorado State University CFDCs}

Online INP measurements were made with two CSU CFDCs, designed for mobile and aircraft deployments but otherwise identical (Eidhammer et al., 2010; DeMott et al., 2015). As described in these previous publications, aerosol flows vertically downward in a central lamina between concentric, cylindrical walls that are ice coated and thermally controlled at different temperatures. Setting a temperature difference between the colder (inner) and warmer (outer) ice walls in the upper "growth" region establishes a nearly steady-state relative humidity $(\mathrm{RH})$ where ice nucleation and ice crystal growth can occur over a few seconds. The temperatures of the inner and outer walls are set to the same value in the lower "evaporation" region of the chamber, which promotes evaporation of water droplets and wet aerosols but retains activated ice particles at larger sizes that can be detected as optically distinct for counting as INPs with an optical particle counter. For this study, the aerosol lamina was $15 \%$ of the total volumetric flow of $10 \mathrm{~L} \mathrm{~min}^{-1}$. Filtered and dried air was recirculated as sheath flow $\left(8.5 \mathrm{~L} \mathrm{~min}^{-1}\right)$. Also for this study, a nominal water-supersaturated condition of $105 \% \mathrm{RH}$ was chosen for operation at all temperatures. This selection was made to force activation of cloud droplets on aerosols at temperatures where some proportion could freeze during the transit time in the instruments, allowing for the most direct comparison possible to the offline immersion freezing methods. Previous studies have explored the need to set the RH in CFDC style instruments to values far above those expected in natural clouds (100-101\% RH) in order to mimic this freezing process (Petters et al., 2009; DeMott et al., 2010, 2015). Although DeMott et al. (2015) showed in laboratory studies that operational $\mathrm{RH}$ up to $109 \%$ might be required for full expression of freezing in the CFDC; $105 \%$ is the value that has been consistently used in field studies so that liquid droplets do not survive through the evaporation region and are not counted as false-positive INPs. For mineral dusts, at least, operation at $105 \%$ could miss by up to a factor of 3
(DeMott et al., 2015) INP number concentrations that ultimately activate via immersion freezing or some combination of nucleation mechanisms. It is unknown if this factor exists for all INP types. Hence, no correction factor was applied to the CFDC data here, but the implications of the factor of 3 will be discussed. CFDC measurement uncertainties vary with processing conditions, and they are typically $\pm 0.5^{\circ} \mathrm{C}$ and $2.4 \%$ water relative humidity at $-30^{\circ} \mathrm{C}$ (DeMott et al., 2015).

Aerosol particles at sizes that might confound optical detection of (i.e., be mistakenly counted as) ice crystals were removed upstream of the CFDC using dual single-jet impactors set to a cut-point aerodynamic diameter of $2.4 \mu \mathrm{m}$. This creates a sampling bias for the CFDC vs. other systems that capture larger particles for immersion freezing experiments but is required to assure detection of activated ice crystals that typically exit the CFDC at optical diameters approximately $>4 \mu \mathrm{m}$.

Interval periods of sampling filtered air within the overall sampling period were used to correct for any background frost influences on INP counts. We follow Schill et al. (2016) for correcting sample concentrations for background and for defining confidence intervals for CFDC data, which are represented by error bars in presented plots. Specifically, corrected INP concentrations are the sample concentrations with the interpolated background concentrations subtracted. The standard deviation of INP concentrations derived from the Poisson counting error during both the sample and the interpolated background period was added in quadrature to obtain the INP concentration error. Concentrations are considered significant if they are 1.64 times larger than the INP concentration error, which corresponds to the $Z$ statistic at $95 \%$ confidence for a one-tailed distribution. Consequently, although the lowest limit of detection for $10 \mathrm{~min}$ sampling intervals is $\sim 0.2 \mathrm{~L}^{-1}$, significant data often require in excess of $1 \mathrm{~L}^{-1}$ INP concentrations. As a special sampling aide in these studies, an aerosol concentrator (Model 4240, MSP Corporation) was used upstream of the CFDC in some cases to enhance INP number concentrations and facilitate statistically significant quantification of INP number concentrations. The enhancement of aerosol concentrations using this dual virtual impactor method affects only particles of diameter $>0.5 \mu \mathrm{m}$ and varies from a factor of 10 at this diameter up to a factor of about 140 at sizes above $1 \mu \mathrm{m}$ (Tobo et al., 2013). The concentration factor achieved for ambient INPs then depends on the INP size distribution, which is difficult to know a priori. The methods outlined in Tobo et al. (2013) were followed to define the concentration factor, using the ratio of CFDC INP number concentrations with and without the concentrator under conditions where statistical significance of measurement was achieved without the concentrator. This was assessed over the term of measurements for each site in the study and applied to all CFDC data when using the aerosol concentrator. An example of measurements on and off of the concentrator for one of the sampling periods 
used in this study is shown in the Supplement, Fig. S1. Use of the aerosol concentrator is indicated in individual cases in the data tables, also included in the Supplement.

Particle losses in upstream tubing, the aerosol impactor and the inlet manifold of the CFDC have previously been estimated as $10 \%$ for particles with diameter 0.1 to $0.8 \mu \mathrm{m}$ (Prenni et al., 2009), and we apply this correction to data for this paper.

\subsubsection{North Carolina State University cold stage (CS)}

The design of the North Carolina State University (NC State) CS-supported droplet freezing assay and data reduction methods are described in detail in Wright and Petters (2013) and Hader et al. (2014).

Droplet populations of three distinct droplet size ranges may be investigated in the CS; these are termed pico-, nano-, and microdrops. Picodrops are generated by mixing a $15 \mu \mathrm{L}$ aliquot of bulk suspension (particles placed into liquid by methods outlined below) with squalene and emulsifying the hydrocarbon-water mixture using a vortex mixer. The emulsion is poured into the CS sample tray, consisting of an aluminum dish holding a hydrophobic glass slide. Approximately $400-800$ droplets with a typical diameter of $\sim 85 \mu \mathrm{m}$ are analyzed in this manner for each collected sample. Nanodrops are generated by manually placing drops with a syringe needle tip on a squalene covered glass slide and letting the drops settle to the squalene-glass interface. Approximately 80 droplets are typically analyzed per experiment with a typical diameter of $\sim 660 \mu \mathrm{m}$. Microdrops are placed directly on the hydrophobic glass slide using an electronic micropipette. In contrast to the pico- and nanodrops, these drops are exposed to a dry $\mathrm{N}_{2}$ gas phase. Up to 256 drops of diameter $\sim 1240 \mu \mathrm{m}(1 \mu \mathrm{L})$ can be investigated in a single experiment. For all experiments, the $\mathrm{CS}$ was cooled at a constant rate of $1^{\circ} \mathrm{C} \mathrm{min}^{-1}\left(2^{\circ} \mathrm{C} \mathrm{min}^{-1}\right.$ at Bodega Marine Laboratory), and the number of unfrozen drops was recorded using a microscope in increments of $\mathrm{d} T=0.17^{\circ} \mathrm{C}$ resolution. Temperature uncertainty is based on the manufacturer's (Model TR141-170, Oven Industries) stated tolerance of the cold-plate thermistor $\left( \pm 1^{\circ} \mathrm{C}\right)$. To account for slightly higher temperatures of the squalene relative to the glass slide, a temperature calibration was applied to the drop-freezing data (Hader et al., 2014). The resulting data were inverted to find the cumulative concentration of INPs $\left(C_{\mathrm{INPs}}(T)\right)$ per volume of liquid at temperature, $T$, using the method of Vali (1971):

$C_{\mathrm{INPs}}(T)=-\left(\frac{1}{V}\right) \ln \left(\frac{N_{\mathrm{u}}(T)}{N}\right)$,

where $N_{\mathrm{u}}$ is the unfrozen number of an initial $N$ of liquid entities (droplets in this case) of volume $V$. Conversion to number concentration of INPs per volume of air $\left(n_{\mathrm{INPs}}(T)\right)$ is determined by

$n_{\mathrm{INPs}}(T)=C_{\mathrm{INPs}}(T)\left(\frac{V_{\mathrm{w}}}{V_{\mathrm{s}}}\right)$, where $V_{\mathrm{w}}$ is the volume of liquid suspension (same units as used to compute $\left.C_{\mathrm{INPs}}(T)\right)$ and $V_{\mathrm{s}}$ is the sample volume (L) of air collected.

To minimize sample heterogeneity, only droplets with $78 \mu \mathrm{m}<D_{p}<102 \mu \mathrm{m}$ were included in the calculation of $n_{\mathrm{INPs}}(T)$ for picodrops. No restriction was applied to the nanodrops or microdrops. Furthermore, the warmest $2 \%$ percent of data were removed after the calculation of $C_{\mathrm{INPs}}(T)$ but before plotting for the pico- and nanodrops due to large uncertainty stemming from poor counting statistics (Hader et al., 2014). The INP content of the ultrapure water (see Sect. 2.2) was measured in the above manner between -20 and $-35^{\circ} \mathrm{C}$. The effective INP content was determined by subtracting the background INP numbers from the ultrapure water from observed $n_{\mathrm{INPs}}(T)$. No impurities were detected at $T>-20^{\circ} \mathrm{C}$. Analysis of CS repeat trial data involved binning data into $1{ }^{\circ} \mathrm{C}$ intervals. Confidence intervals were calculated using 2 standard deviations of the geometric mean for each bin where multiple data points were available.

\subsubsection{University of British Columbia MOUDI-DFT}

The second immersion freezing method involved freezing of droplets grown on substrate-collected particles in a temperature- and humidity-controlled flow cell (Mason et al., 2015) and is referred to as the droplet freezing technique (DFT). A micro-orifice uniform deposit impactor (MOUDI; MSP Corp.) was used to size-select particles from known volumes of air onto a substrate for direct DFT analysis in a number of cases (MOUDI-DFT, Mason et al., 2015). The MOUDI collected size-selected particles onto multiple hydrophobic glass cover slips (HR3-215; Hampton Research). For the measurements performed in Kansas, United States, stages 2-9 of the MOUDI were used corresponding to particle size bins of 10-5.6, 5.6-3.2, 3.2-1.8, 1.8-1.0, 1.0-0.56, $0.56-0.32,0.32-0.18$ and $0.18-0.10 \mu \mathrm{m}(50 \%$ cutoff aerodynamic diameter; Marple et al., 1991), respectively. For the measurements at CSU, stages 2-8 were used; for the measurements at Manitou (Colorado) Experimental Forest Observatory (MEFO), stages 2-7 were used.

For DFT analysis, droplets were grown in the flow cell by decreasing temperature to $0{ }^{\circ} \mathrm{C}$ and passing a humidified flow of He gas over the slides. Water was allowed to condense until approximately $100 \mu \mathrm{m}$ diameter water droplets formed on the collected particles, typically covering several to some tens of particles, depending on loading. Droplets were then monitored for freezing using a coupled optical microscope (Axiolab; Zeiss, Oberkochen, Germany) with a $5 \times$ magnification objective, as temperature was lowered at a constant rate. A charge-coupled device connected to the optical microscope recorded a digital video, while a resistance temperature detector recorded the temperature. A cooling rate of $10^{\circ} \mathrm{C} \mathrm{min}^{-1}$ (from 0 to $-40^{\circ} \mathrm{C}$ ) was used in these studies to minimize freezing of droplets due to contact of a growing crystal and to minimize evaporation of unfrozen droplets 
due to the Bergeron-Findeisen process, i.e., growth of the existing ice crystals at the expense of the surrounding liquid droplets (Mason et al., 2015). The liquid droplet may evaporate, or the frozen droplet will grow towards and eventually contact a liquid droplet, causing it to freeze. If a droplet is lost to evaporation or to non-immersion freezing, two assumptions are made:

1. That the droplet contained an INP and would have frozen by immersion (on its own) at the same temperature as the non-immersion/evaporation event. This gives an upper limit to the calculated INP concentration

2. That the droplet contained no INPs and would not have frozen until homogeneous temperatures, which are around $-36{ }^{\circ} \mathrm{C}$ in the flow cell used. This assumption provides a lower limit to the calculated INP concentration at a given $T$.

The method to obtain the INP number concentrations in air follows a similar basis as for the CS but with modest differences:

$n_{\mathrm{INPs}}(T)=-\ln \left(\frac{N_{\mathrm{u}}(T)}{N}\right) N\left(\frac{A_{\text {deposit }}}{A_{\mathrm{DFT}} V_{\mathrm{s}}}\right) f_{\mathrm{nu}} f_{\mathrm{ne}}$,

where $N$ is the total number of droplets condensed onto the sample in this case, $A_{\text {deposit }}$ is the total area of the sample deposit on the hydrophobic glass cover slip, ADFT is the area of the sample monitored in the digital video during the droplet freezing experiment and $V_{\mathrm{S}}$ is the volume of air sampled by the MOUDI. $f_{\text {ne }}$ is a correction factor to account for the statistical uncertainty that results when only a limited number of nucleation events are observed. $f_{\text {ne }}$ was calculated following the approach given in Koop et al. (1997) using a $95 \%$ confidence interval. $f_{\text {nu }}$ is a correction factor to account for non-uniformity in particle concentration across each MOUDI sample (Mason et al., 2015, 2016). This later correction factor consists of two multiplicative terms: $f_{\text {nu, } 1 \mathrm{~mm}}$ and $f_{\text {nu, }} 0.25-0.10 \mathrm{~mm}$, with these terms correcting for non-uniformity in the particle deposits at the $1 \mathrm{~mm}$ and $0.25-0.1 \mathrm{~mm}$ scale, respectively. Since only a small area $\left(1.2 \mathrm{~mm}^{2}\right)$ of the particle deposits are analyzed and the concentration of particles are not uniform across the entire substrate, $f_{\text {nu, } 1 \mathrm{~mm}}$ needs to be applied. Since the concentration of particles are not uniform within the small area of the particle deposits analyzed for freezing, $f_{\mathrm{nu}}, 0.25-0.10 \mathrm{~mm}$ needs to be applied. Listed in Tables S3 and S4 are the $f_{\text {nu, } 1 \mathrm{~mm}}$ and $f_{\text {nu, }}, 25-0.10 \mathrm{~mm}$ values applied to the MOUDIDFT samples collected at CSU and Kansas, respectively. Different correction factors were used for the CSU and Kansas samples since different substrate holders were used to position the glass slides within the MOUDI at the two sites. Substrate holders were not yet employed during the earlier MEFO studies (Huffman et al., 2013). However, by using saved slides from the MEFO experiments, estimates could be made of the slide offset positions that are needed for defining the non-uniformity correction at the $1 \mathrm{~mm}$ scale in Mason et al. (2015). Listed in Table S5 are the $f_{\mathrm{nu}, 1 \mathrm{~mm}}$ correction factors applied to the MEFO samples based on the slide offset positions. Data were not taken on the nonuniformity within the field of view during the freezing experiments $\left(f_{\text {nu }}, 0.10-0.25 \mathrm{~mm}\right)$ for the MEFO collections, and hence no correction was applied to the MEFO samples for non-uniformity at the $0.25-0.1 \mathrm{~mm}$ scale. On the basis of Mason et al. (2015; cf. Fig. 8 of that paper) and calculations using the factors found for CSU and Kansas sampling, the inability to quantify $f_{\text {nu, } 0.10-0.25 \mathrm{~mm}}$ will lead to an underprediction of $n_{\text {INPs }}(T)$ by a factor that depends on the frozen fraction of droplets at any temperature, perhaps as high as 1.7 for the first drops freezing ( 1 of $~ 50-100$, or $1-2 \%$ frozen fraction) but less than 1.1 once $25 \%$ of droplets have frozen.

Confidence intervals (95\%) were calculated based on the Poisson distribution, following Koop et al. (1997). These intervals are nearly equivalent to Binomial confidence intervals for the data in this study.

\subsubsection{Colorado State University IS}

The CSU ice spectrometer (IS) (Hill et al., 2014, 2016; Hiranuma et al., 2015) measures freezing in an array of liquid aliquots held in a temperature-controlled block. For IS processing, aerosol particles in suspensions are distributed into 24 to 48 aliquots of $40-80 \mu \mathrm{L}$ held in sterile 96 -well PCR trays ( $\mu$ Cycler, Life Science Products). The numbers of wells frozen are counted at 0.5 or $1^{\circ} \mathrm{C}$ intervals during cooling at a rate of $0.33{ }^{\circ} \mathrm{C} \mathrm{min}^{-1}$. Temperature was measured with $0.1^{\circ} \mathrm{C}$ resolution and $0.4^{\circ} \mathrm{C}$ accuracy (Hill et al., 2016). Calculation of $n_{\mathrm{INPs}}(T)$ was made using Eqs. (1) and (2), where $V$ was the aliquot volume. Control wells of ultrapure water (see Sect. 2.2) were also cooled, and correction for any frozen aliquots in the pure water control vs. temperature was made in all cases, similar to the CS method. Binomial sampling confidence intervals $(95 \%)$ were determined for IS data, as described in Hill et al. (2016).

\subsubsection{National Institute of Polar Research CRAFT}

The Cryogenic Refrigerator Applied to Freezing Test (CRAFT) device has been described in detail by Tobo (2016). CRAFT is a classical cold-plate device akin to the DFT and the CS instruments, but it involves procedures to assure sample isolation, primarily from the cold-plate surface using a layer of Vaseline ${ }^{\circledR}$. Droplets containing collected aerosols are pipetted in a clean hood onto the coated aluminum plate that is then set on the stage of a portable Stirling-enginebased refrigeration device (CRYO PORTER, Model CS80CP, Scinics Corporation). The freezing device is also operated in a booth that is aspirated with clean air. The temperature of the plate was measured using a single temperature sensor, and the uncertainty of temperature is $0.2{ }^{\circ} \mathrm{C}$. 
For each CRAFT measurement, 49 droplets with a volume of $5 \mu \mathrm{L}$ were used, and the temperature was lowered at a rate of $1^{\circ} \mathrm{C} \mathrm{min}{ }^{-1}$ until all the droplets froze. Results of control experiments with pure water droplets were used to correct for any contamination introduced by water. Each freezing experiment was monitored by a conventional video camera. Video image analysis was used to establish the number fractions of droplets frozen and unfrozen at $0.5^{\circ} \mathrm{C}$ intervals. Analyses of $n_{\text {INPs }}(T)$ followed the same scheme as used for the CS and IS measurements. Binomial confidence intervals (95\%) were determined, as for the IS data.

\subsection{Aerosol collection methods and processing for immersion freezing studies}

At different times, ambient aerosol samples were collected directly into liquid or onto filters, for subsequent resuspension into liquid. Collection directly into liquid was done using a glass bioaerosol sampler (SKC Inc.), hereafter termed the BioSampler. This unit was typically placed on a table at $1.2 \mathrm{~m}$ above ground level. The BioSampler directs particles into a sample cup filled with $20 \mathrm{~mL}$ of ultrapure water $(18.2 \mathrm{M} \Omega \mathrm{cm}$ resistivity and $0.02 \mu \mathrm{m}$ filtered using an Anotop syringe filter (Whatman, GE Healthcare Life Sciences)), where they impinge to form an aqueous suspension. Particle collection efficiencies for this technique exceed $80 \%$ for particles larger than $200 \mathrm{~nm}$ and approach $100 \%$ for particles larger than $1 \mu \mathrm{m}$ (Willeke et al., 1998). Particles with diameter $D_{\mathrm{p}}>10 \mu \mathrm{m}$ are expected to impact the inlet wall (Hader et al., 2014). Sample flow rate was $12.5 \mathrm{~L} \mathrm{~min}^{-1}$, and impaction liquid was replenished every 20-30 min by adding ultrapure water into the collection cup.

For IS-only and some shared samples, particles were also collected onto pre-sterilized $47 \mathrm{~mm}$ diameter Nuclepore ${ }^{\mathrm{TM}}$ track-etched polycarbonate membranes (Whatman, GE Healthcare Life Sciences). Filters were pre-cleaned by soaking in $10 \% \mathrm{H}_{2} \mathrm{O}_{2}$ for $10 \mathrm{~min}$, followed by three rinses in ultrapure water, and were dried on foil in a particle-free, laminar flow cabinet. Filters were held open-faced in sterile Nalgene filter units (Thermo Scientific, Rochester, NY). Flow rates varied from about 8 to $13 \mathrm{~L} \mathrm{~min}^{-1}$ for ambient temperature and pressure conditions in different studies. Collection onto $0.2 \mu \mathrm{m}$ pore-diameter filters was typical, although comparison vs. $3 \mu \mathrm{m}$ pore-diameter filters was also done in some initial experiments. Both filter types were of $\sim 10 \mu \mathrm{m}$ average thickness and $15 \%$ porosity. On the basis of theoretical collection efficiencies (Spurny and Lodge, 1972), the $0.2 \mu \mathrm{m}$ pore filters should have collected particles of all sizes with very high efficiency, the lowest efficiency being at about $0.1 \mu \mathrm{m}(\sim 80 \%)$. In contrast, the filters with $3 \mu \mathrm{m}$ pores are expected to collect 15 and $55 \%$ of all particles at sizes of 0.4 and $1 \mu \mathrm{m}$, respectively, increasing to $>75 \%$ collection at sizes above $1.5 \mu \mathrm{m}$. In this manner, the larger pore size emphasizes the contributions of supermicron aerosols to immersion freezing INPs.
After particle collection, filters were stored frozen at -25 or $-80^{\circ} \mathrm{C}$ in sealed, sterile Petri dishes until they could be processed (few hours to few months). BioSampler samples were similarly stored frozen and processed over similar time frames. MOUDI collections for the DFT method were vacuum-sealed after collection and stored at $4{ }^{\circ} \mathrm{C}$ in a refrigerator; shipping was done with cold packs prior to coldstage flow cell measurements at the University of British Columbia. We therefore assume similar impacts, if any, of storage on INPs following thawing for processing.

This study was not initially conceived as one to test storage impacts on INPs, which should be addressed in future research. We do not expect storage methods to impact results on the basis of existing documentation in the literature. For example, in their study of INPs in rainwater, Petters and Wright (2015) noted that the argument that INP activity remains unaltered by the freezing of samples and subsequent storage for some time is at the core of the general application of immersion freezing methods. They noted, with reference to other literature, the generally better than $1^{\circ} \mathrm{C}$ repeatability of freezing temperatures for droplets that undergo repeated freeze-thaw cycles.

For processing of INP freezing spectra, filters were transferred to sterile, $50 \mathrm{~mL}$ Falcon polypropylene tubes (Corning Life Sciences), immersed in $7.0-10.0 \mathrm{~mL}$ of ultrapure water and tumbled for $30 \mathrm{~min}$ in a rotator (Roto-Torque, ColePalmer) to suspend particles in liquid. Common liquid suspensions were shared amongst methods in some cases (see Sect. 2.3), following freezing and shipping to different investigators. We detected no measurable impact of processing rinsed suspensions immediately vs. after freezing of the bulk water, mostly supported by other recent studies (Beall et al., 2017). We will note that while all immersion freezing methods performed tests comparing freezing of the liquid samples and the purified water used in their setups, and corrected for pure water freezing events, no correction is made for any INPs that might be released from the filters used for collection. We have found that filters release a modest number of INPs active at lower temperatures, even after the pre-cleaning with $\mathrm{H}_{2} \mathrm{O}_{2}$ and purified water. A detailed analysis of this will be presented in a future publication. The percentages of undiluted INPs due to such contamination is $\sim 3 \%$ in the -25 to $-30{ }^{\circ} \mathrm{C}$ range, and since immersion freezing measurements at these temperatures require dilution of liquid samples by 100 to 3000 times, we neglected any corrections.

\subsection{Sampling sites/periods and objectives}

Sampling sites represent a variety of ecosystems, climates and elevations across the western US, including agricultural regions of the US High Plains, intermountain desert regions and a coastal site. The majority of data included in this intercomparison involved periods that did not include all groups and were not temporally aligned for all instrument systems. Nevertheless, substantial overlap of sampling periods oc- 
Table 1. Samples taken during periods when the CFDC was operated at a single temperature on each date and when immersion freezing methods were aligned in time, sharing samples in some cases. Data from Waverly, CO, are from Garcia et al. (2012). Sample volumes ranged from 1600 to $5500 \mathrm{~L}$.

\begin{tabular}{|c|c|c|c|c|c|}
\hline Location & Lat, long. & $\begin{array}{r}\text { Date } \\
(\mathrm{MM} / \mathrm{DD} / \mathrm{YYYY})\end{array}$ & $\begin{array}{r}\text { Elevation } \\
(\mathrm{m})\end{array}$ & $\begin{array}{l}\text { Standard sample } \\
\text { type }\end{array}$ & Instruments \\
\hline Waverly, CO & $40.761,-105.076$ & $\begin{array}{l}9 / 29 / 10 \\
10 / 4 / 10 \\
10 / 8 / 10 \\
11 / 3 / 10\end{array}$ & 1585 & $\begin{array}{l}\text { BioSampler } \\
\text { BioSampler } \\
\text { BioSampler } \\
\text { BioSampler }\end{array}$ & $\begin{array}{l}\text { CFDC, IS } \\
\text { CFDC, IS } \\
\text { CFDC, IS } \\
\text { CFDC, IS }\end{array}$ \\
\hline $\begin{array}{l}\text { CSU Atmos Chem, } \\
\text { Fort Collins, CO }\end{array}$ & $40.587,-105.150$ & $\begin{array}{r}9 / 6 / 13 \\
9 / 6 / 13 \\
9 / 6 / 13 \\
9 / 6 / 13 \\
9 / 6 / 13 \\
9 / 12 / 13 \\
9 / 12 / 13 \\
9 / 12 / 13 \\
11 / 12 / 13 \\
11 / 12 / 13 \\
11 / 12 / 13 \\
11 / 13 / 13 \\
11 / 13 / 13 \\
11 / 13 / 13 \\
11 / 14 / 13\end{array}$ & 1591 & $\begin{array}{l}\text { Ultrapure water } \\
\text { BioSampler blank } \\
\text { BioSampler } \\
3 \mu \mathrm{m} \text { filter } \\
0.2 \mu \mathrm{m} \text { filter } \\
\text { BioSampler } \\
3 \mu \mathrm{m} \text { filter } \\
0.2 \mu \mathrm{m} \text { filter } \\
\text { BioSampler } \\
3 \mu \mathrm{m} \text { filter } \\
0.2 \mu \mathrm{m} \text { filter } \\
\text { BioSampler } \\
3 \mu \mathrm{m} \text { filter } \\
0.2 \mu \mathrm{m} \text { filter } \\
\text { BioSampler }\end{array}$ & $\begin{array}{l}\text { CFDC, IS, CS } \\
\text { CFDC, IS, CS } \\
\text { CFDC, IS, CS } \\
\text { CFDC, IS, CS } \\
\text { CFDC, IS, CS } \\
\text { CFDC, IS } \\
\text { CFDC, IS } \\
\text { CFDC, IS } \\
\text { CFDC, IS, CS, MOUDI-DFT } \\
\text { CFDC, IS, CS, MOUDI-DFT } \\
\text { CFDC, IS, CS, MOUDI-DFT } \\
\text { CFDC, IS, CS, MOUDI-DFT } \\
\text { CFDC, IS, CS, MOUDI-DFT } \\
\text { CFDC, IS, CS, MOUDI-DFT } \\
\text { CFDC, IS, CS, MOUDI-DFT }\end{array}$ \\
\hline
\end{tabular}

curred in all cases. Very often, the CFDC sampling was conducted to obtain data at multiple temperatures, while offline collections were made for longer periods to obtain integrated INP temperature spectra. Times when the sampling periods were the same for the offline systems and for the CFDC, while it was operating at a single temperature, are listed in Table 1. Other site locations, characteristics and instruments participating when there were overlapping sample periods are listed in Table 2.

\subsubsection{Colorado State University, Fort Collins, CO, USA}

Sampling was conducted outside of the atmospheric chemistry building at Colorado State University at different times and including different methods. The laboratory site is on a small hill on the western edge of the Fort Collins urban area, residing amongst surrounding grasslands. Initially, a series of measurement days were conducted in which collections for three immersion freezing methods were made while the CFDC sampled at a single temperature for the entire sampling period. While this protocol permitted only a single comparison point vs. the temperature spectra obtained by offline measurements, the purpose was to obtain a statistically significant CFDC $n_{\mathrm{INPs}}(T)$ value during the course of time-integrated offline samples and to assure that any signal variance occurring during sampling was the same for all measurements. Such aligned sampling was conducted on five different days (see Table 1). Participating in these temporally aligned experiments were the IS, CS and MOUDI-
DFT instruments. For these periods, the filter sampling units, BioSampler and (when used) MOUDI sampling units were set in close proximity and at the same sampling elevation. Filter suspensions from the two pore-size $(0.2$ and $3.0 \mu \mathrm{m})$ filter collections and from the BioSampler were shared for IS and CS measurements. All CS data were analyzed using the pico- and nanodrop technique.

Sampling was also conducted at CSU without exact temporal overlap of CFDC, IS and CRAFT method measurements, as noted in Table 2. CRAFT filters $(0.2 \mu \mathrm{m}$ pore size $)$ were drawn for $6 \mathrm{~h}$ at a flow rate of $10 \mathrm{~L} \mathrm{~min}^{-1}$ at standard temperature and pressure (STP) conditions ( $T=273 \mathrm{~K}$, $1013.5 \mathrm{mb})$. IS filter $(0.2 \mu \mathrm{m}$ pore size $)$ were drawn for $4 \mathrm{~h}$ at a flow rate of $13 \mathrm{~L} \mathrm{~min}^{-1}$ at ambient temperature and pressure. The CFDC sample was temporally aligned with the IS sample, and single operating temperatures were used.

\subsubsection{Northern Colorado, USA, agricultural region}

Sampling over previously harvested fields during fall 2010 was conducted at a rural site approximately $26 \mathrm{~km} \mathrm{NNE}$ of the CSU atmospheric chemistry building, at Grant Family Farms, near the village of Waverly, CO. The sampling field sites on different days, the sampling protocol and the results used in the present study are discussed in detail by Garcia et al. (2012). Sampling by CFDC and IS (BioSampler) were temporally overlapped in this study. This site is referred to as NoCO in the data tables in the Supplement. 
Table 2. Sampling locations, elevations, dates and instruments involved in sampling at field sites when the CFDC sampled at varied temperatures during integral offline collections. All sampling at these sites was by filters except for the use of a BioSampler for the CS at Bodega Bay Marine Laboratory, the IS at Waverly, and the MOUDI-DFT at Manitou Experimental Forest (Huffman et al., 2013) and Colby (Mason et al., 2015). CFDC data from Manitou Experimental Forest are from Tobo et al. (2013). Data from Waverly, CO, are from Garcia et al. (2012).

\begin{tabular}{|c|c|c|c|c|c|}
\hline Region & Location & Lat, long. & Date & Elevation (m) & Instruments \\
\hline Forest & $\begin{array}{l}\text { Manitou Experimental } \\
\text { Forest Observatory, CO }\end{array}$ & $39.094,-105.101$ & $\begin{array}{l}8 / 17 / 11 \\
8 / 18 / 11\end{array}$ & 2370 & $\begin{array}{l}\text { CFDC, } \\
\text { MOUDI-DFT }\end{array}$ \\
\hline Agricultural & Waverly, CO & $40.761,-105.076$ & $\begin{array}{c}9 / 29 / 10 \\
10 / 4 / 10 \\
10 / 8 / 10 \\
11 / 3 / 10\end{array}$ & 1585 & CFDC, IS \\
\hline Agricultural & Colby, KS & $39.394,-101.066$ & $\begin{array}{l}10 / 14 / 14 \\
10 / 15 / 14\end{array}$ & 966 & CFDC, IS, MOUDI-DFT \\
\hline Agricultural & Lamont, OK & $36.607,-97.488$ & $\begin{array}{c}4 / 30 / 14 \\
5 / 4 / 14 \\
5 / 5 / 14 \\
6 / 5 / 14 \\
6 / 7 / 14 \\
6 / 8,14\end{array}$ & 315 & CFDC, IS \\
\hline Coastal & $\begin{array}{l}\text { Bodega Bay Marine } \\
\text { Laboratory, CA }\end{array}$ & $39.307,-123.066$ & $\begin{array}{r}1 / 26 / 15 \\
2 / 2 / 15\end{array}$ & 5 & CFDC, IS, CS \\
\hline Semi-arid & Canyonlands, UT & $38.071,-109.563$ & $\begin{array}{l}5 / 11 / 16 \\
5 / 12 / 16\end{array}$ & 1627 & CFDC, IS, CRAFT \\
\hline Semi-rural & $\begin{array}{l}\text { CSU Atmos Chem, } \\
\text { Fort Collins, CO }\end{array}$ & $40.587,-105.150$ & $\begin{array}{l}5 / 18 / 16 \\
5 / 19 / 16\end{array}$ & 1591 & CFDC, IS, CRAFT \\
\hline
\end{tabular}

\subsubsection{Manitou Experimental Forest, CO, USA}

Sampling within an open forest site at MEFO as part of the Bio-hydro-atmosphere interactions of Energy, Aerosols, Carbon, $\mathrm{H}_{2} \mathrm{O}$, Organics \& Nitrogen project (Ortega et al., 2014) during summer 2011 was conducted as described by Huffman et al. (2013), Prenni et al. (2013) and Tobo et al. (2013). Only two selected periods from that study for which there was partial overlap of samples from the CFDC and MOUDIDFT methods were available for this study.

\subsubsection{Kansas, USA, agricultural region}

Sampling periods were conducted in and around the times of different crop harvesting at Kansas State University Northwest Research Extension Center in Colby, KS, as part of a larger study. Sampling periods used for this study were during mornings before or evenings following harvesting of various crops and during daytime near fields being harvested of soy and sorghum crops. CFDC sampling was conducted from the CSU Mobile Laboratory facility, using gasolinepowered generators, as described previously by McCluskey et al. (2014). The mobile laboratory was in all cases well upwind of the generators. Aerosols were sampled through an inlet comprised of a stainless-steel rain hat with a $1 / 2 \mathrm{in}$.
OD stainless-steel tube attached. MOUDI-DFT (Mason et al., 2016) and filter samples were collected with their inlets at the same approximate elevation as the CFDC inlet and used separate pumps for drawing samples. The CFDC scanned different temperatures during the IS filter $(0.2 \mu \mathrm{m})$ and MOUDI-DFT sampling periods.

\subsubsection{Southern Great Plains (SGP), USA, site}

The site at Lamont, OK (Table 2), is the central instrumentation suite location for the US Department of Energy's Atmospheric Radiation Measurement Climate Research Facility SGP field site. CFDC and IS instruments both drew air from a platform at $10 \mathrm{~m}$ above ground elevation at this site. Sampling occurred in a transition from dry to wet conditions in the spring of 2014. The CFDC was operated to scan temperatures during the IS filter $(0.2 \mu \mathrm{m})$ sampling period. A selection of representative days of data were chosen, and full study data will be included in a separate publication.

\subsubsection{Bodega Marine Laboratory, CA, USA}

Sampling near Bodega Bay, CA (BBY in subsequent figures), occurred during the CalWater-2015 study (Ralph et al., 2015; Martin et al., 2016). The sampling site was at the 

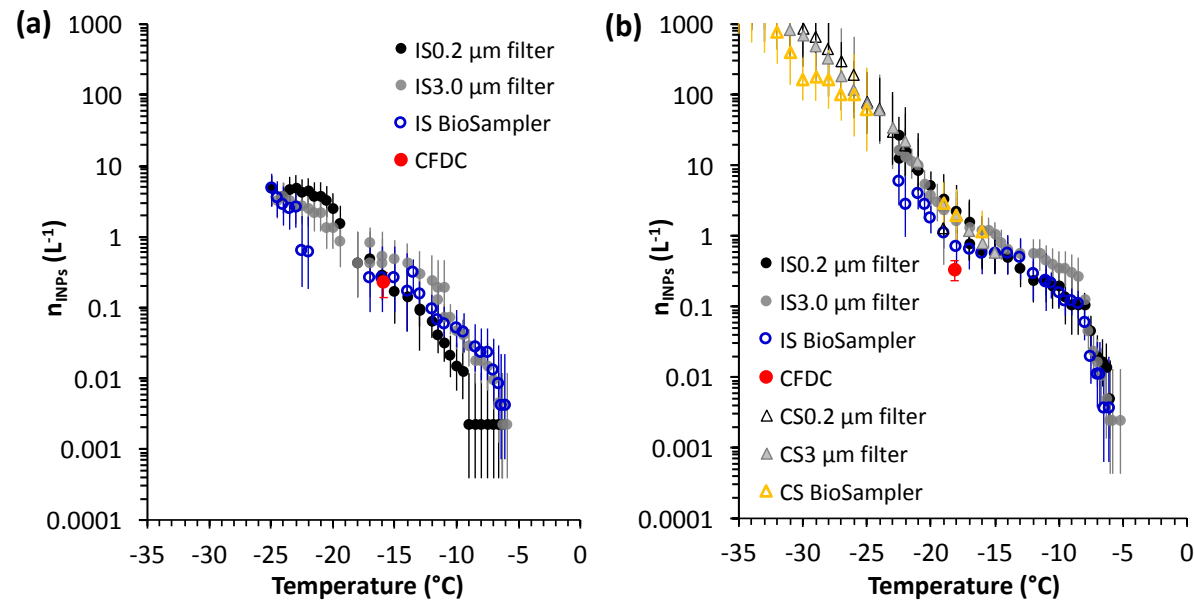

Figure 1. Temperature spectra of INP number concentrations ( $n_{\mathrm{INP}}$ ) from IS and CS measurements and a CFDC measuring at a single temperature over a $4 \mathrm{~h}$ sampling period. Ambient aerosols were sampled outside of the Colorado State University atmospheric chemistry building on (a) 12 September 2013 and (b) 6 September 2013. Temperature spectra were separately measured for simultaneously collected filter samples with different pore sizes and liquid samples from a BioSampler. Uncertainty values (95\% confidence intervals) are shown.

University of California, Davis Bodega Marine Laboratory, $\sim 100 \mathrm{~m}$ ENE of the seashore and $\sim 30 \mathrm{~m}$ north of the northernmost permanent building at the site (Martin et al., 2016). The CFDC and IS instruments sampled from approximately $4 \mathrm{~m}$ above the surface. The CFDC was operated to scan temperatures during the IS filter $(0.2 \mu \mathrm{m})$ sampling period. CS BioSampler samples, overlapping with IS and CFDC sampling, were drawn from an elevation of $1 \mathrm{~m}$ above the vegetated surface, approximately $20 \mathrm{~m}$ west of the other samplers. All BBY CS data are analyzed using the microdrop technique. A few representative days are chosen from the data set for comparison of IS and CS data with CFDC data. Comparison of the complete CS and IS data sets will be included in a publication in preparation.

\subsubsection{Canyonlands Research Center, UT, USA}

The Nature Conservancy's Canyonlands Research Center is an intermountain (Rocky Mountains, US), high-desert site located adjacent to Canyonlands National Park in SE Utah. Sampling occurred in May of 2016. IS and CRAFT filters were drawn at $1.2 \mathrm{~m}$ above ground, the same elevation as the CFDC inlet. CRAFT filters were drawn for $6 \mathrm{~h}$ at a flow rate of $10 \mathrm{~L} \mathrm{~min}^{-1}$ at STP conditions ( $T=273 \mathrm{~K}, 1013.5 \mathrm{mb}$ ), at this site and at CSU. IS filters $(0.2 \mu \mathrm{m}$ pore size $)$ were drawn for $6 \mathrm{~h}$ at a flow rate of $13 \mathrm{~L} \mathrm{~min}^{-1}$. CFDC sampling overlapped with the IS filter period, but operating temperature was varied.

\section{Results}

\subsection{Comparison of cases with perfect temporal overlap of sample data collections}

Figure 1a compares IS and CFDC data for two $4 \mathrm{~h}$ study periods at the CSU site. In the figure CFDC INP concentrations at $-16^{\circ} \mathrm{C}$ are integrated and averaged for the entire IS filter sampling period for comparison to IS data collected both on filters and using the BioSampler. Considering the capture efficiencies vs. size noted in Sect. 2.2, the lack of significant difference in IS $n_{\text {INPs }}(T)$ measured with the filters of 0.2 and $3 \mu \mathrm{m}$ pore sizes implies that most INPs were likely large enough to be captured effectively. This crudely suggests an INP mode size at about $1 \mu \mathrm{m}$ or larger. This is also a size that is collected with high efficiency in the BioSampler, for which similar INP concentrations were measured. This example also shows the uncertainties in temperature spectra of INP number concentration from the IS. In this case, one can see a range of about a factor of 4 in INP number concentration and an equivalent range of $2-4{ }^{\circ} \mathrm{C}$ using different collection methods, and in consideration of confidence in measurements made at any particular temperature. The CFDC data collected using the aerosol concentrator are in agreement within uncertainties of all particle collection methods in this case.

In Fig. 1b, results are shown from a case where filter rinse suspension and BioSampler suspension were also shared with the CS instrument for offline processing of samples collected from the CSU site on 6 September 2013. There is significant overlap between the IS and CS data in the temperature range from -6 to $-23^{\circ} \mathrm{C}$ (the lowest temperature limit of IS processing for these particular experiments). No sig- 

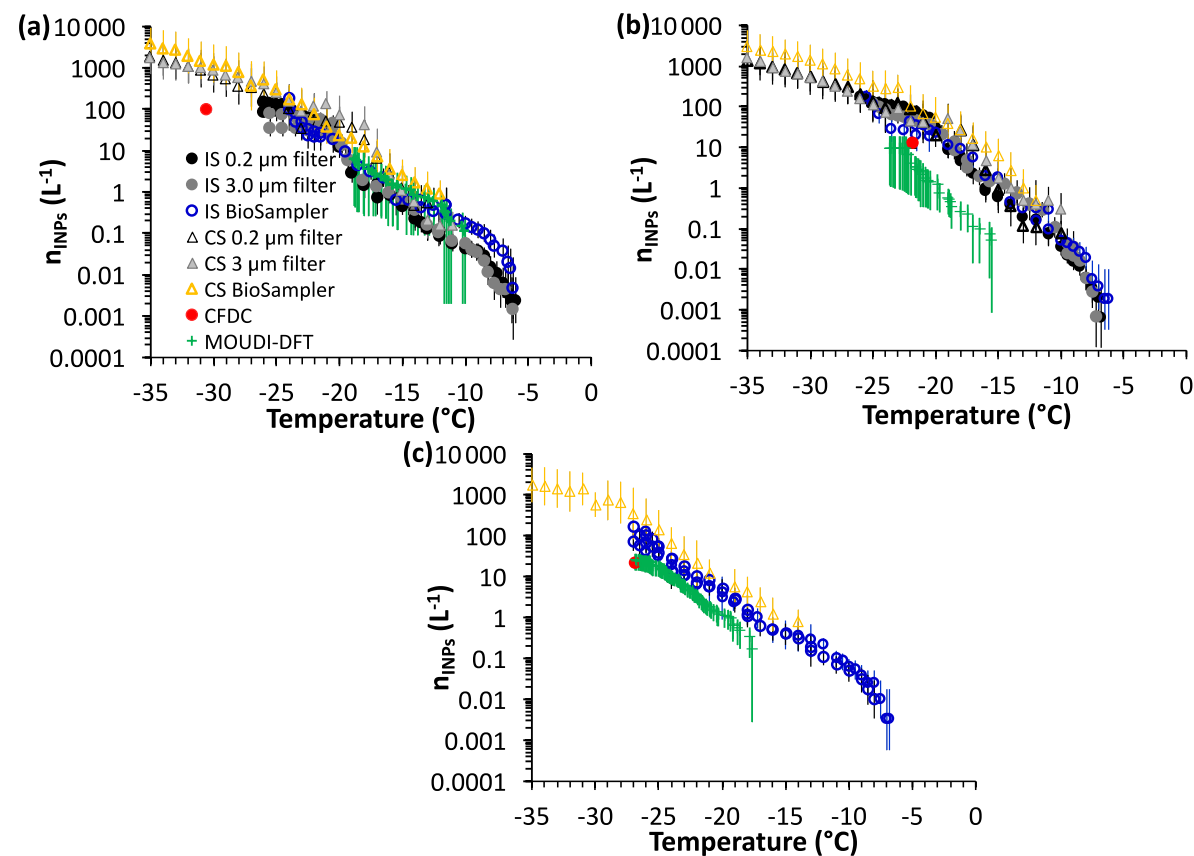

Figure 2. Three additional experimental comparison days, as in Fig. 1 but for cases where all four methods were operational for consistent sampling periods. These dates were $12-14$ November in panels (a)-(c), respectively. The legend is shown in panel (a). The additional data in green are from the MOUDI-DFT method (all sizes included), including median (cross) and upper and lower bounds.

nificant bias is discernable between IS and CS data for any of the collection methods. Once again, correspondence of the CFDC data (using the aerosol concentrator in this case) with other methods is good at a processing temperature of $-18.2^{\circ} \mathrm{C}$. However, the CFDC data fall a factor of $2-5$ lower than the immersion freezing methods. This is similar to data reported in Garcia et al. (2012) for which the discrepancy was attributed primarily to the failure of the CFDC instrument to sample larger aerosols. Nevertheless, results from this sampling day support the conclusions of general agreement between methods obtained in Fig. 1a.

Figure 2 shows results from three additional cases for which there was perfect temporal co-sampling by the CFDC, IS, CS and MOUDI-DFT methods. In these cases, the IS and CS shared samples of particles collected during the same time period, while the MOUDI-DFT was operated independently. We note that the error bars on MOUDI data reflect upper- and lower-bound estimates, as discussed in Sect. 2.1.3. Figure 2 highlights not only some points already made but also the occurrence of a range of discrepancies in $n_{\text {INPs }}(T)$ between the MOUDI-DFT and other methods, and for CFDC data collected simultaneously at temperatures below $-20^{\circ} \mathrm{C}$. The $\mathrm{CS}$ method typically measures the highest $n_{\text {INPs }}(T)$ overall for the same collections of aerosols (filter or BioSampler), suggesting a temperature offset of at least $1{ }^{\circ} \mathrm{C}$ between these systems that may have as its source the temperature measurement of the liquid wells or drops. The MOUDI-DFT results trend with the other immersion freez- ing methods on all days but agree quantitatively with them on only one of three days (Fig. 2a) and fall lower than $n_{\text {INPs }}(T)$ determined by the CS and IS on two other days: by a factor of 2 to 5 (Fig. 2c) in one case and 20 to 50 in the other (Fig. 2b). These two cases have been discussed previously in Mason et al. (2015), and we will revisit the largest discrepancies in both cases in later discussion. Similar to the MOUDI-DFT results, the CFDC data also show a consistent underestimate of $n_{\mathrm{INPs}}(T)$ compared to the CS and IS in all three cases, with a trend that increases from a factor of 2-4 at $-23^{\circ} \mathrm{C}$ up to 10 times at $-30^{\circ} \mathrm{C}$ (Fig. 2a).

\subsection{Comparison for cases of imperfect temporal overlap of sample data collections}

The data shown in Figs. 1 and 2, for which there was complete temporal overlap of observations, provide a limited number of evaluations of measurement correspondence and uncertainties that may occur due to different size ranges of collection and natural variations in INP compositions and concentrations that may occur over varied sampling times as measured across the mixed-phase cloud temperature regime. This situation will surely be improved in future studies as many different instrument teams worldwide begin to compare data collected at common sites. To expand understanding, we considered all cases in which the CFDC was sampling simultaneously with other methods but without the restriction of a single CFDC processing temperature for the full sampling period. There are also cases when the offline 

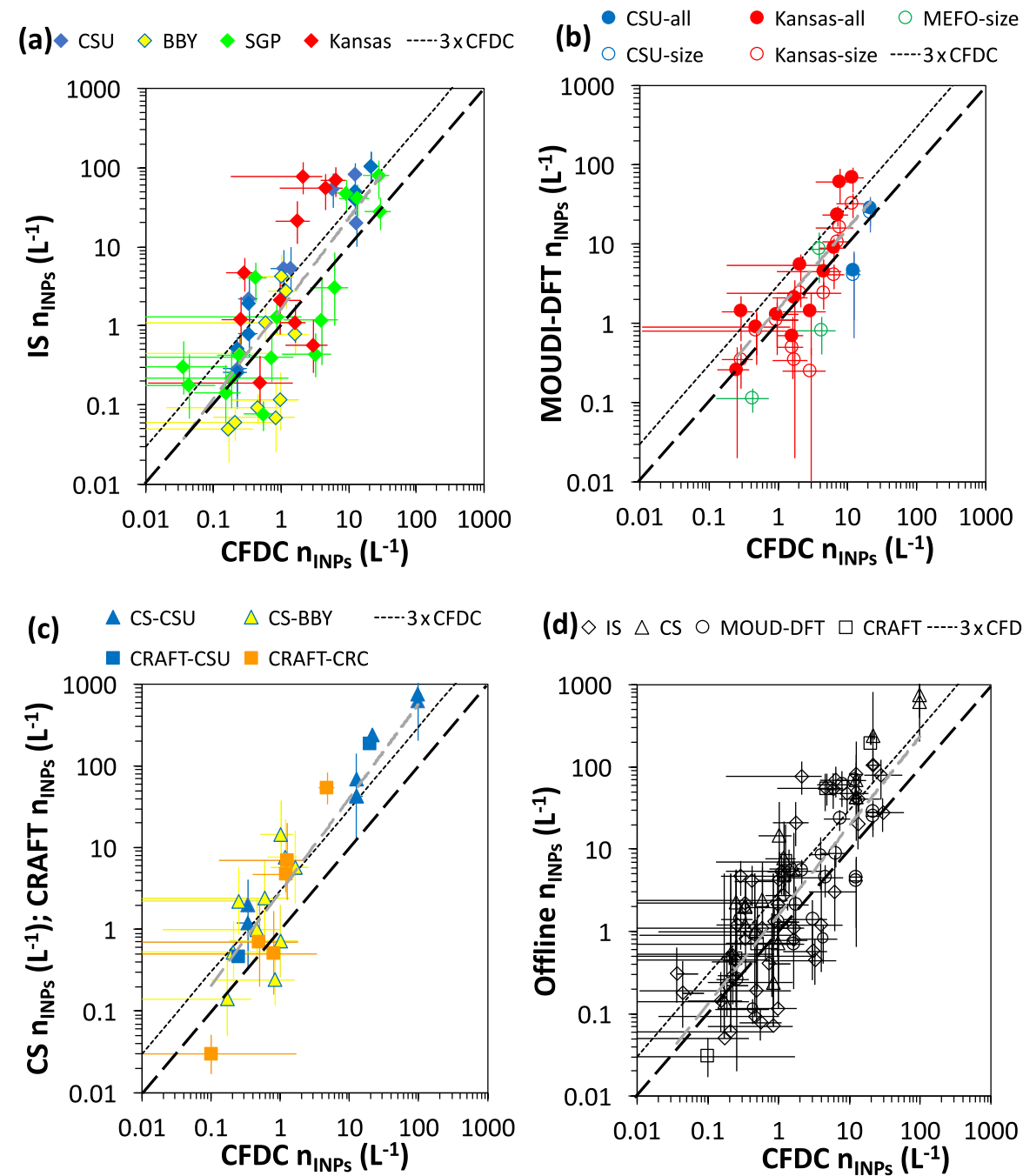

(d) $\diamond$ IS $\triangle$ CS O MOUD-DFT $\square$ CRAFT ---.-3xCFDC

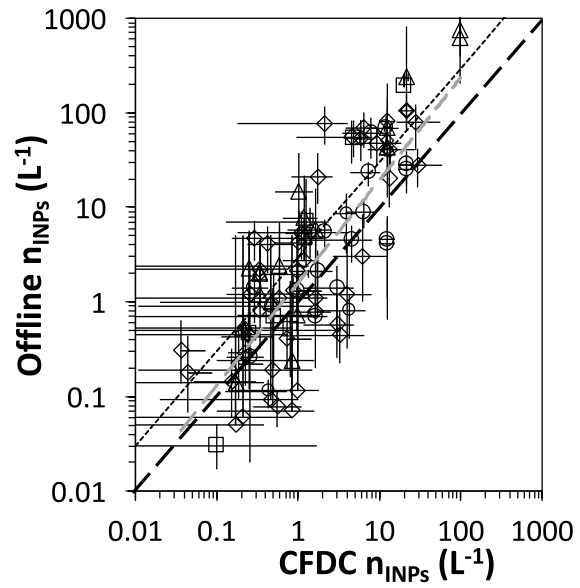

Figure 3. Scatterplot of INP number concentrations obtained with different immersion freezing methods plotted against CFDC online measurement results obtained at $105 \% \mathrm{RH}$ and temperatures ranging from approximately -15 to $-31^{\circ} \mathrm{C}$ : (a) IS, (b) MOUDI-DFT (medians of data such as shown in Fig. 1), (c) CS and CRAFT, (d) all data combined from offline immersion freezing tests. The MOUDI-DFT data in (b) include data for all particles sizes assessed ("all") and for the particle size range of 0.3-3.2 $\mu$ m ("size") best aligned with the effective CFDC sampling size range. Error bars represent $95 \%$ confidence intervals, as defined for each method. Light dashed gray lines are simple linear relations intended only to guide the eye.

sample periods overlapped but did not perfectly align. Thus, while seeking further insights by folding in data from additional times and collection sites, we must acknowledge that such comparisons leave open the possibility that temporal variability may impact comparison of methods. Nevertheless, this replicates many field study situations where multiple ice nucleating instruments may be deployed but may not sample for the same time periods.

In Fig. 3, we combine periods of perfect sampling overlap with these other cases for which one or more of the immersion freezing methods were performed for a few-hour period, during which CFDC sampling intervals (typically 10-15 min at a single temperature) occurred. Comparison of the CFDC and IS measurements is shown in Fig. 3a. These results reinforce those in Fig. 2, indicating that the IS assessment of $n_{\mathrm{INPs}}(T)$ agrees on average with the CFDC-measured values when the CFDC processed particles at $105 \% \mathrm{RH}$ at the lower end of the dynamic range of $n_{\mathrm{INPs}}(T)$. The IS method, however, measures higher concentrations than the CFDC at higher $n_{\mathrm{INPs}}(T)$, resulting in a non-unity relational slope. The linear relational slope between IS and CFDC data is shown by the light gray dashed line in Fig. 3a. The same representation is applied in all panels of Fig. 3. We provide these fits only to show general trends between the different data sets and do not provide fit parameters herein because a deeper consideration of the source of discrepancies 
requires additional inspection of trends as a function of temperature, which follows below. Higher $n_{\mathrm{INPs}}(T)$ typically occur at lower temperatures. Results are similar regardless of measurement site, but with relatively high variability in the relation between single CFDC and IS measurements even at a single site, and with greater discrepancy in the data set from Colby, KS, which we suggest is the result of an abundance of larger INPs not sampled by the CFDC during this harvesting period.

The MOUDI-DFT data show the best correspondence overall vs. the CFDC measurements (Fig. 3b), irrespective of whether all aerosol sizes are considered for the DFT measurement or are limited to a range of particle sizes similar to those entering the CFDC. There is a slight positive bias for the MOUDI-DFT method when all sizes are considered, as expected given the CFDC limitation on particle sizes sampled.

Overlapping comparisons between the CS and CFDC, and CRAFT and CFDC, while more limited (Fig. 3c), show a relatively high bias of the CS and CRAFT data, most exaggerated at higher $n_{\mathrm{INPs}}(T)$ and correlated with lower temperatures as discussed shortly.

Overall comparisons by offline methods vs. the CFDC are shown in Fig. 3d. These demonstrate that, although a consistent linear (but not $1: 1$ ) relationship could be inferred between offline immersion freezing and CFDC measurements, discrepancies for all methods and sampling times taken together at a CFDC $n_{\mathrm{INP}}(T)$ of $1 \mathrm{~L}^{-1}$ can reach nearly 2 orders of magnitude. Discrepancies appear to reduce to within about 1 order of magnitude at higher $n_{\text {INPs }}(T)$, although the degree to which this is real or the result of a smaller number of cases is not yet clear. We may note of course that CFDC measurements have their greatest uncertainties in the range of concentrations at or below $1 \mathrm{~L}^{-1}$.

The same data sets used in Fig. 3, and compiled in Table S1 in the Supplement, are used in Fig. 4 to explore the temperature dependence of immersion freezing measurement results vs. the CFDC when all sampling scenarios are considered (multiple aerosol scenarios, perfect or imperfect overlap of sampling times). In examining the IS vs. CFDC comparisons (Fig. 4a), the scatter in the relation is again the most striking feature, while the temperature-dependent bias also becomes clear to a greater or lesser degree at all sampling sites, the least at CSU and the SGP site, and the most at Bodega Bay and in the harvesting period in Kansas. The strong positive bias of INP measurements by the IS at lower temperatures in Kansas is not consistent with the fact that larger INPs $(>2.5 \mu \mathrm{m})$, which are not sampled by the CFDC, are not thought to dominate INPs at lower temperatures (Mason et al., 2016). A more modest positive temperature bias is noted in comparing MOUDI and CFDC concentrations vs. temperature at below $-25^{\circ} \mathrm{C}$ (Fig. 4b), and the underestimate of INP concentrations due to the elimination of coarse-mode aerosols in CFDC sampling ranges from about 2 to 4 times (see MOUDI "all" vs. "size" in Fig. 4b),
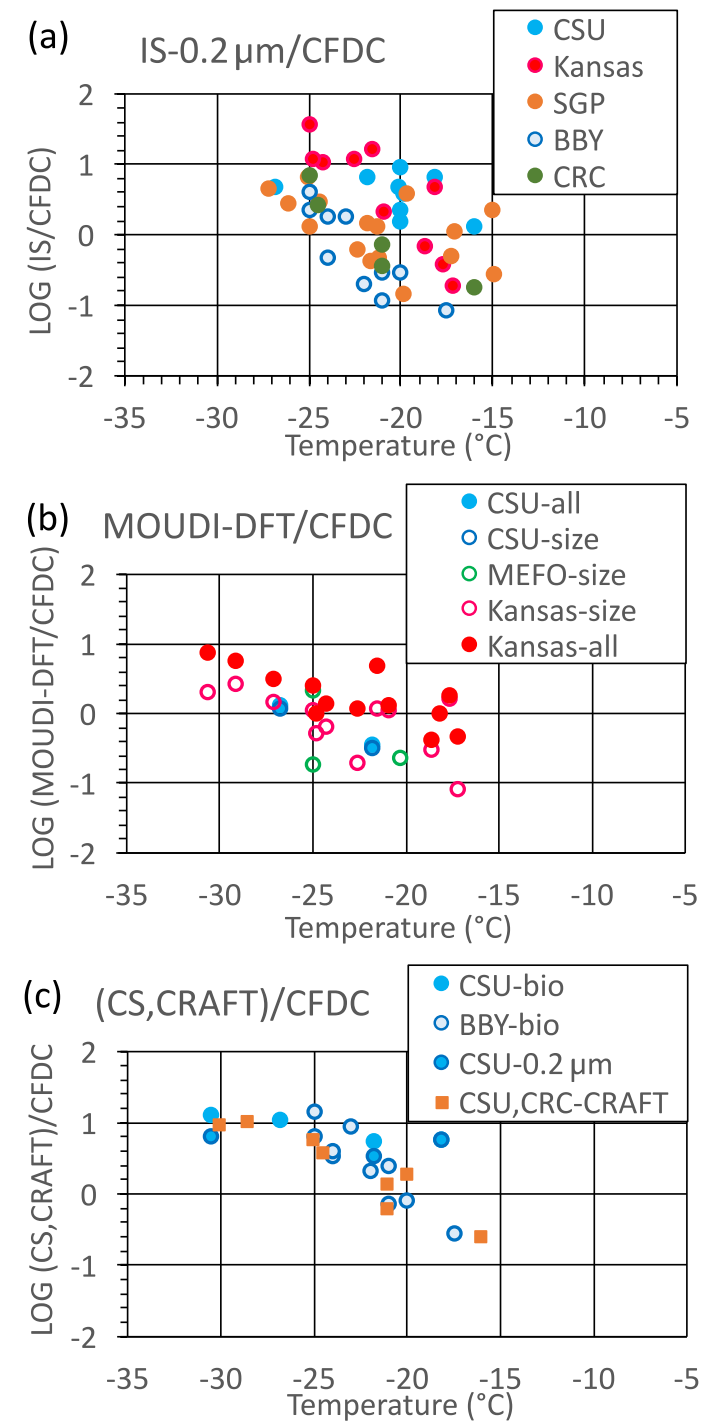

Figure 4. Base 10 logarithm of the ratio of INP number concentrations measured by various immersion freezing methods vs. the CFDC at different sites, denoted as in previous figures. IS $0.2 \mu \mathrm{m}$ filter samples are shown in (a) from five sites. MOUDI-DFT data are compared from three sites in (b), where "size" and "all" refer to whether INP number concentrations are from MOUDI size ranges overlapping with sizes permitted into the CFDC or from all sizes. $\mathrm{CS}$ and CRAFT ratios are shown in (c), where all blue points are for the CS, and "bio" refers to BioSampler collections.

consistent with the estimates of coarse-mode INP fractions by Mason et al. (2016). We may note similarly good agreement between INP concentrations measured by the CFDC and DFT methods across similar temperature ranges for marine aerosols (DeMott et al., 2016). Strong positive biases of CS- and CRAFT-measured INP concentrations vs. the CFDC measurements are seen to progressively occur as temperatures decrease from -20 to $-30^{\circ} \mathrm{C}$ (Fig. $4 \mathrm{c}$ ). 


\section{Discussion}

In this section, we summarize observations regarding comparisons of the INP measurement methods and discuss potential reasons for discrepancies that bear future investigation. It has been shown that there are times when multiple measurement techniques give excellent agreement for $n_{\mathrm{INPs}}(T)$ in the immersion freezing mode. Agreement is best at temperatures warmer than $-20^{\circ} \mathrm{C}$ and for $n_{\mathrm{INPs}}(T)$ less than $\sim 5 \mathrm{~L}^{-1}$. At lower temperatures and higher $n_{\mathrm{INPs}}(T)$, most offline immersion freezing methods, with the exception of MOUDIDFT, estimate higher than the online CFDC method, by ratios ranging from a few to 10 times. We must caution that the overall range of $n_{\mathrm{INPs}}(T)$ assessed and values present at different temperatures may reflect the aerosol measured at ground level at the selected sites and times, scenarios that may not represent all locations and times worldwide. Nor may these results be the same if the comparisons were made entirely for free-tropospheric aerosols, for example as assessed from an aircraft or at some mountaintop sites. Nevertheless, the potential issues in obtaining agreement between methods will be common in any sampling scenario.

A factor in any series of immersion freezing measurements is the time dependence of nucleation. In a study of the time-dependent freezing of kaolinite particles, Welti et al. (2012) demonstrated that the majority of freezing occurred within about a period of $10 \mathrm{~s}$ or less at the temperatures -30 to $-37^{\circ} \mathrm{C}$, with $0.8 \mu \mathrm{m}$ diameter particles needing far less time for activation than $0.4 \mu \mathrm{m}$ particles. Studies of freezing rates for other natural INP types across broader temperature ranges indicate that immersion freezing is indeed not a purely stochastic process and is far more sensitive to temperature, with the consequence that the increase in $n_{\mathrm{INPs}}(T)$ achieved when droplets remain at a single temperature for periods longer than seconds to minutes is typically overcome by a few degrees of additional cooling (Vali, 2014; Wright et al., 2013). The CFDC $n_{\mathrm{INPs}}(T)$ attributed here to immersion freezing were obtained for a total processing time of approximately $7 \mathrm{~s}$, during the last $2 \mathrm{~s}$ of which activated droplets are evaporating (DeMott et al., 2015). This residence time is constrained by flow rates required for limiting thermally driven reverse flow circulations in the CFDC. By comparison to the Welti et al. (2012) study, it seems likely that the CFDC activation times allow for capturing the majority of immersion freezing activity in most circumstances. Nevertheless, we expect that the CFDC might underestimate $n_{\text {INPs }}(T)$ to a greater extent than the IS measurements, which are made while ramping at a very slow cooling rate equivalent to $1{ }^{\circ} \mathrm{C}$ in $3 \mathrm{~min}$. Since the DFT uses much faster cooling rates $\left(5-10^{\circ} \mathrm{C} \mathrm{min}^{-1}\right)$, this might explain the better correspondence with the CFDC data. However, it cannot explain the temperature-dependent nature of the bias between other immersion freezing methods and the CFDC, and so it seems not to be the only source of this discrepancy.

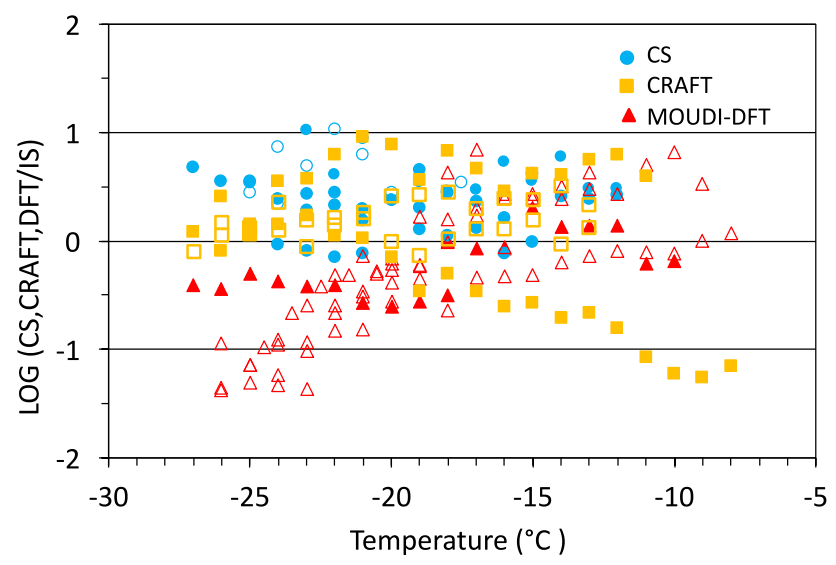

Figure 5. Immersion freezing methods comparison, shown as the base 10 logarithm of the ratio of the CS, CRAFT and MOUDI-DFT method INP concentrations for perfect or imperfect overlap of cosampling periods with the IS INP number concentrations. Samples collected outside the CSU atmospheric chemistry facility are shown as filled symbols, while samples collected at other sites on different days (CS: Bodega Bay; CRAFT: Canyonlands Research Center; DFT: Colby, KS) are shown as open symbols.

Here we must also reiterate that the processing of submicron-mode mineral dust particles at $105 \% \mathrm{RH}$ in the CFDC has been shown to underestimate $n_{\mathrm{INPs}}(T)$ by an average temperature-independent factor of 3 , as confirmed by laboratory cloud chamber simulations. This factor was related to the fact that higher $\mathrm{RH}$ is typically required to fully activate all particles (hygroscopic or hydrophobic) as droplets to subsequently be available for freezing in the CFDC residence time (DeMott et al., 2015; Garimella et al., 2017). However, practical operation of the CFDC at higher RH (109\% may be required for full activation) is prohibited in sampling of natural aerosol distributions because the largest aerosols could persist as droplets through the evaporation section of the instrument under these conditions, thus contaminating INP determination using optical sizing. Hence, it is unknown if natural INP populations are being underestimated for similar reasons. Based on the recent study of Garimella et al. (2017), it seems possible that underestimation of INP concentrations occurs for CFDC-style instruments independent of the aerosol type. Consequently, lines indicating a factor of 3 higher than the $1: 1$ relation have been placed on plots in the panels of Fig. 3. While it is noted that increasing the CFDC $n_{\mathrm{INPs}}(T)$ by a factor of 3 leads to better overall agreement of CFDC data with the CS and CRAFT data especially, this constant expected offset does not explain the progressive underestimate of the CFDC in comparison to most immersion freezing methods (the IS, CS and CRAFT being most like other methods used worldwide) at higher $n_{\mathrm{INPs}}(T)$ and lower temperatures.

A factor that could artificially increase $n_{\mathrm{INPs}}(T)$ at lower temperatures in methods that immerse the entire aerosol pop- 
ulation first into liquid (IS, CS, CRAFT) is the potential breakup of aggregates containing multiple INPs (e.g., via the deflocculation of small aggregates as a result of the strong reduction in di- and trivalent cation concentrations in the deionized water used for making dilution series, or by the fragmentation of mucigels (Hill et al., 2016)) and the possible dissolution release of surface-active INP materials present on single particles when suspended in deionized water (O'Sullivan et al., 2016). It seems possible that such action would have the greatest impact on INPs active at lower temperatures (rather than the most active INPs), since these may be small clay/organic matter aggregates or flocs that fragment when exposed to deionized water. Since the MOUDI-DFT method immerses a relatively small number of particles directly and without agitation in small drops prior to freezing, it is interesting to note that the least temperature-dependent bias occurs for these measurements in comparison to the CFDC. This point is shown more clearly by comparing only the offline immersion freezing methods in Fig. 5. In this figure, the different measured INP concentrations are taken as a ratio vs. the IS, which sampled the most times and scenarios. Data at $1^{\circ}$ temperature resolution are included in this comparison, as compiled in Table S2. Again, relatively high variability of at least 1 order of magnitude at any temperature is noted for the relations between methods. Among methods that involve immersion of all particles in a single volume of water prior to setting up arrays (CS, CRAFT, IS), the IS falls to the low side of the other measurements by an average factor of about 2.5. This is not a significant difference, in consideration of the likely temperature uncertainties discussed in relation to Figs. 1 and 2. The MOUDI-DFT method that immerses relatively small populations of particles shows relative equivalence to the full immersion methods at modest to moderately supercooled temperatures but measured consistently lower INP concentrations at below about $-20^{\circ} \mathrm{C}$ in the few cases when co-sampling was conducted with the IS (CSU and Kansas). This is consistent with the discrepancy seen also vs. CFDC data. Interestingly, a lower-temperature enhancement of INPs appearing in full immersion methods vs. continuous flow methods was not observed in recent laboratory tests comparing many measurement methods while sampling mineral, soil dust and biological particle samples that had been purposely limited to sizes smaller than $2 \mu \mathrm{m}$ (DeMott et al., 2017). While this points to coarse-mode particles and their dissolution/fragmentation into multiple INP units as the source of differences, future experiments will be needed to confirm or deny that this is either an artifact or a behavior in natural aerosols that the CFDC cannot effectively capture.

Particle size limitations lead to CFDC underestimates of $n_{\mathrm{INPs}}(T)$ in comparison to some immersion freezing methods. This is because of the need to remove particles larger than $2.4 \mu \mathrm{m}$. This removal of larger aerosols is necessary when differentiating grown ice crystals from aerosols by size alone. Even absent the use of impactors, it would be diffi- cult for most online systems to effectively sample larger particles due to the design of inlet systems. With reference to the study of Mason et al. (2016), which entailed sampling with the MOUDI-DFT method at various sites, one might estimate that on average about $50 \%$ of INPs are at sizes larger than $2.4 \mu \mathrm{m}$ in the surface boundary layer. Comparison of MOUDI-DFT with CFDC data in this study is consistent with this same estimate (Fig. 3b). Again, this would not apparently explain a progressive slight increase in CFDC underestimation vs. the MOUDI-DFT at lower temperatures unless larger INPs specially dominate ice nucleation at lower temperatures, a result not consistent with Mason et al. (2016).

In evaluating the low-temperature discrepancies by noting the better correspondence of MOUDI-DFT and CFDC methods, it is also necessary to note the potential issue of particle bounce in the MOUDI in some cases (Mason et al., 2016). While the conditions for this to occur are not well quantified, since both INP size and phase state (as this may be influenced by low relative humidity) may affect bounce, very dry conditions have been indicated as times when this may become an issue for MOUDI impaction onto the substrates used in the DFT instrument. Interestingly, average RH during the sampling period on 13 November 2013 (Fig. 2b) was between 15 and $20 \%$ vs. $40-45 \%$ for days on either side (Fig. 2a, c), potentially impacting and explaining the MOUDI-DFT results on this day. For this reason, this day was excluded in Figs. 35. Sample humidification of the system could mitigate this factor as a potential issue in future sampling.

\section{Conclusions}

This study has inspected the correspondence of ice nucleation measurement systems for co-sampling ambient ice nucleating particles. In this case, we considered systems for measuring immersion freezing nucleation with a common online method used in a manner to induce activation of cloud droplets prior to ice nucleation. Very good agreement within uncertainty limits was obtained under many conditions for samples that had perfect temporal overlap. In other cases, discrepancies can approach 2 orders of magnitude and are not explicable without inferring systematic artifacts inherent to one or more techniques. The results summarized in Fig. 3d show the uncertainties that can be expected when employing one or more of these instrument systems for measuring atmospheric INPs. Within these uncertainties, the data suggest that the low bias of immersion freezing methods reported by Hiranuma et al. (2015) for sampling of individual surrogate dusts in the laboratory was not evident in these ambient data sets.

With regard to particle sampling methods for immersion freezing measurements, use of a BioSampler or a filter was interchangeable, at least for the continental boundary layer sampling for which these methods were compared. This was demonstrated for individual and for cross-technique methods 
(IS vs. CS) for assessing immersion freezing from the same samples. Since Nuclepore filters seem to efficiently capture and release INPs, these provide ease-of-use benefits in many field scenarios, although the role of retention of particles on some filter types has not been assessed here. Potential effects of sample storage protocol also remain to be investigated.

The strongest discrepancies between methods appear at both warmer and colder ends of the scale of mixed-phase cloud freezing temperatures. At the warmer end $(T>$ $-20^{\circ} \mathrm{C}$ ), sampling statistics and uncertainties can dominate comparisons of online and offline methods. Full explanations for the maximum 2-orders-of-magnitude range of variation in this temperature regime remain unresolved. In contrast, at lower temperatures the IS, CS and CRAFT methods measured more INPs than detected by the CFDC and MOUDIDFT. Potential artifacts or biases are present in these comparisons and have been discussed here, including varied assessment of time dependence of ice nucleation; necessary exclusion of larger INPs by online instruments such as the CFDC; and immersion of all particles into relatively large volumes of deionized water in most, but not all, immersion freezing methods vs. activation of single particles in CFDCs. In addition, it is expected that all CFDC-type instrument data may require correction for not being able to access full immersion of particles until higher RH than can commonly be used when sampling ambient particles, or else this issue requires future mitigation (e.g., insertion of particles into the instrument lamina could be improved). Hence, no assured conclusions regarding the sources of discrepancies can be stated at this time except that size biases in sampling need to be acknowledged. Effort thus remains to make INP measurements fully quantitative and comparative across methods if correspondence within less than 1 order of magnitude is desired. Even amongst standard immersion freezing methods, uncertainties of a factor of a few $n_{\mathrm{INPs}}(T)$ and $2-4{ }^{\circ} \mathrm{C}$ are likely common on the basis of this study and may be the best that can be achieved. Application of size selection to immersion freezing collections for comparison to MOUDIDFT data (especially at lower temperatures) and CFDC data; information on INP compositions inferred under all sampling scenarios to help constrain influences of various types (e.g., methods of Hill et al., 2016); and an intercomparison of all methods vs. a cloud parcel simulation chamber, considered as a de facto standard, would all assist resolution and improvement of understanding of measurement discrepancies.

Data availability. Specific data sets are available through referenced studies, and all data used in figures in this manuscript are tabulated in the Supplement. 
Appendix A: Acronyms and symbols (in italics) used

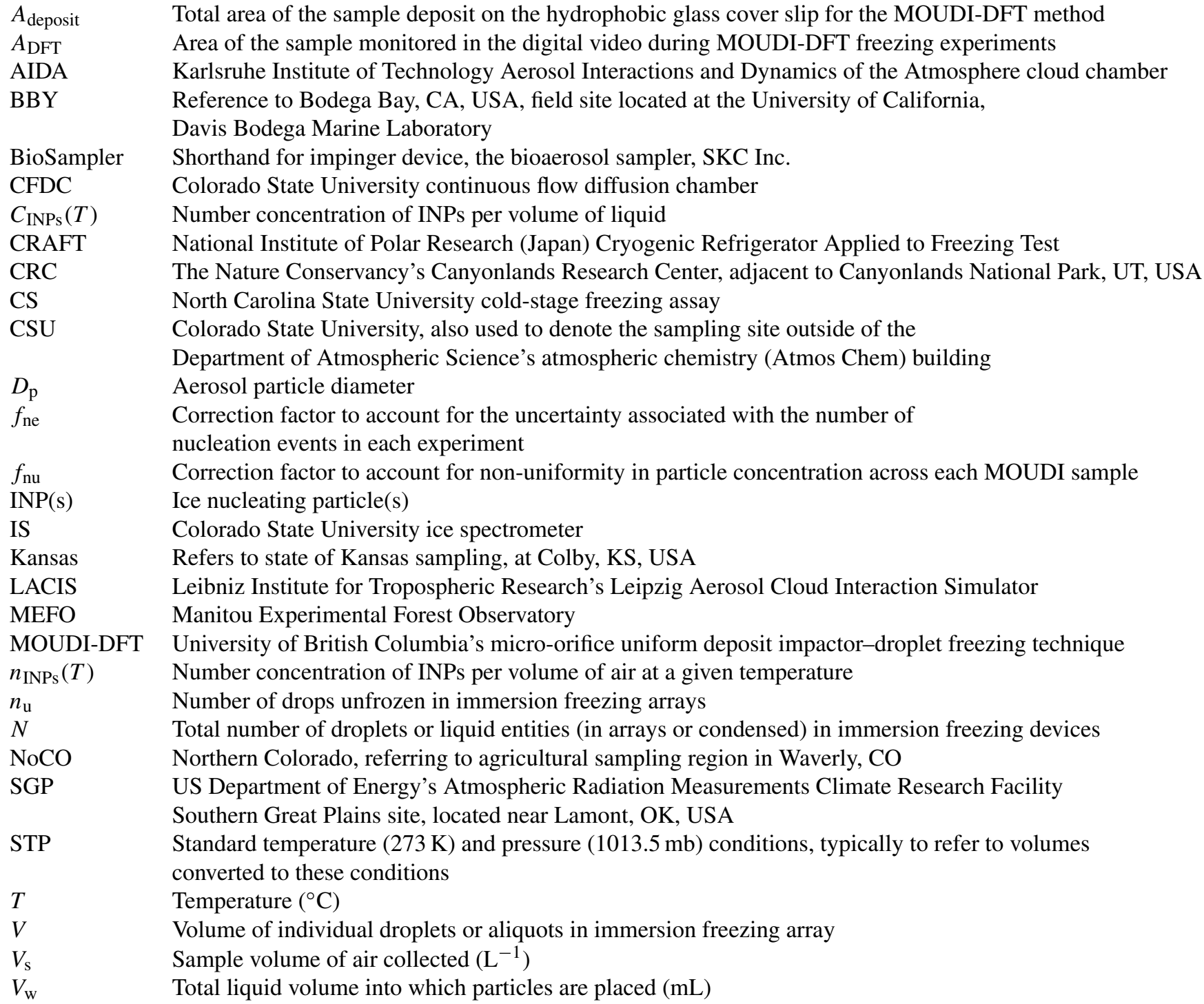




\section{The Supplement related to this article is available online at https://doi.org/10.5194/acp-17-11227-2017- supplement.}

Competing interests. The authors declare that they have no conflict of interest.

Acknowledgements. Funding for this work was provided by National Science Foundation grants AGS1358495 (Paul J. DeMott, Thomas C. J. Hill, Kaitlyn J. Suski and Ezra J. T. Levin), AGS1010851 (Markus D. Petters and John D. Hader), AGS1450690 (Markus D. Petters, Nicholas Rothfuss and Hans P. Taylor), AGS1450760 (Paul J. DeMott, Thomas C. J. Hill, Christina S. McCluskey and Sonia M. Kreidenweis) and AGS1433517 (Gregory P. Schill). Support for operations at the US Department of Energy's Southern Great Plains site was provided by the Atmospheric Radiation Measurement (ARM) Climate Research Facility, a US Department of Energy Office of Science user facility sponsored by the Office of Biological and Environmental Research. Allan K. Bertram, Ryan H. Mason and Cedric Chou acknowledge support of the Natural Sciences and Engineering Research Council of Canada. Yutaka Tobo acknowledges support from the Japan Society for the Promotion of Science (JSPS, KAKENHI grant numbers 15K13570 and 16H06020), Japan's National Institute of Polar Research (NIPR, Project Research KP-3) and the Arctic Challenge for Sustainability (ArCS) project. Yvonne Boose thankfully acknowledges support from the Zeno Karl Schindler foundation. Special thanks to Kim Prather, Andrew Martin and colleagues at the University of California, San Diego for their logistical support during studies at Bodega Bay. We also thank the University of California, Davis Bodega Marine Laboratory for the use of laboratory and office space and shipping and physical plant support while collecting data. We thank the National Park Service and Jeffrey Collett for use of their respective mobile laboratories during various field study deployments. We thank Freddie Lamm, Dan Foster and Marv Farmer at the Kansas State University Northwest Research Extension Center for their help with coordinating the measurements. Finally, we thank the Nature Conservancy's Canyonlands Research Center and Field Station Manager Philip Adams for helping arrange and select sites for measurements there.

Edited by: Anne Perring

Reviewed by: two anonymous referees

\section{References}

Beall, C. M., Stokes, M. D., Hill, T. C., DeMott, P. J., DeWald, J. T., and Prather, K. A.: Automation and heat transfer characterization of immersion mode spectroscopy for analysis of ice nucleating particles, Atmos. Meas. Tech., 10, 2613-2626, https://doi.org/10.5194/amt-10-2613-2017, 2017.

Boose, Y., Sierau, B., García, M. I., Rodríguez, S., Alastuey, A., Linke, C., Schnaiter, M., Kupiszewski, P., Kanji, Z. A., and Lohmann, U.: Ice nucleating particles in the Sa- haran Air Layer, Atmos. Chem. Phys., 16, 9067-9087, https://doi.org/10.5194/acp-16-9067-2016, 2016.

DeMott, P. J., Prenni, A. J., Liu, X., Kreidenweis, S. M., Petters, M. D., Twohy, C. H., Richardson, M. S., Eidhammer, T., and Rogers, D. C.: Predicting global atmospheric ice nuclei distributions and their impacts on climate, P. Natl. Acad. Sci. USA, 107, 1121711222, 2010.

DeMott, P. J., Prenni, A. J., McMeeking, G. R., Sullivan, R. C., Petters, M. D., Tobo, Y., Niemand, M., Möhler, O., Snider, J. R., Wang, Z., and Kreidenweis, S. M.: Integrating laboratory and field data to quantify the immersion freezing ice nucleation activity of mineral dust particles, Atmos. Chem. Phys., 15, 393-409, https://doi.org/10.5194/acp-15-393-2015, 2015.

DeMott, P. J., Hill, T. C. J., McCluskey, C. S., Prather, K. A., Collins, D. B., Sullivan, R. C., Ruppel, M. J., Mason, R. H., Irish, V. E., Lee, T., Hwang, C. Y., Rhee, T. S., Snider, J. R., McMeeking, G. R., Dhaniyala, S., Lewis, E. R., Wentzell, J. J. B., Abbatt, J., Lee, C., Sultana, C. M., Ault, A. P., Axson, J. L., Diaz Martinez, M., Venero, I., Santos-Figueroa, G., Stokes, M. D., Deane, G. B., Mayol-Bracero, O. L., Grassian, V. H., Bertram, T. H., Bertram, A. K., Moffett, B. F., and Franc, G. D.: Sea spray aerosol as a unique source of ice nucleating particles, P. Natl. Acad. Sci. USA, 113, 5797-5803, https://doi.org/10.1073/pnas.1514034112, 2016.

DeMott, P. J. et al.: Overview of results from the Fifth International Workshop on Ice Nucleation - Part 2 (FIN-02): Laboratory intercomparisons of ice nucleation measurements, Atmos. Chem. Phys., in preparation, 2017.

Eidhammer, T., DeMott, P. J., Prenni, A. J., Petters, M. D., Twohy, C. H., Rogers, D. C., Stith, J., Heymsfield, A., Wang, Z., Haimov, S., French, J., Pratt, K., Prather, K., Murphy, S., Seinfeld, J., Subramanian, R., and Kreidenweis, S. M.: Ice initiation by aerosol particles: Measured and predicted ice nuclei concentrations vs. measured ice crystal concentrations in an orographic wave cloud, J. Atmos. Sci., 67, 2417-2436, https://doi.org/10.1175/2010JAS3266.1, 2010.

Emersic, C., Connolly, P. J., Boult, S., Campana, M., and Li, Z.: Investigating the discrepancy between wet-suspensionand dry-dispersion-derived ice nucleation efficiency of mineral particles, Atmos. Chem. Phys., 15, 11311-11326, https://doi.org/10.5194/acp-15-11311-2015, 2015

Garcia, E., Hill, T. C. J., Prenni, A. J., DeMott, P. J., Franc, G. D., and Kreidenweis, S. M.: Biogenic ice nuclei in boundary layer air over two U.S. High Plains agricultural regions, J. Geophys. Res. 117, D18209, https://doi.org/10.1029/2012JD018343, 2012.

Garimella, S., Rothenberg, D. A., Wolf, M. J., David, R. O., Kanji, Z. A., Wang, C., Rösch, M., and Cziczo, D. J.: Uncertainty in counting ice nucleating particles with continuous flow diffusion chambers, Atmos. Chem. Phys., 17, 10855-10864, https://doi.org/10.5194/acp-17-10855-2017, 2017.

Grawe, S., Augustin-Bauditz, S., Hartmann, S., Hellner, L., Pettersson, J. B. C., Prager, A., Stratmann, F., and Wex, H.: The immersion freezing behavior of ash particles from wood and brown coal burning, Atmos. Chem. Phys., 16, 13911-13928, https://doi.org/10.5194/acp-16-13911-2016, 2016.

Hader, J. D., Wright, T. P., and Petters, M. D.: Contribution of pollen to atmospheric ice nuclei concentrations, Atmos. Chem. Phys., 14, 5433-5449, https://doi.org/10.5194/acp-145433-2014, 2014. 
Hill, T. C. J., Moffett, B. F., DeMott, P. J., Georgakopoulos, D. G., Stump, W. L., and Franc, G. D.: Measurement of ice nucleation-active bacteria on plants and in precipitation by quantitative PCR, Appl. Environ. Microbiol., 80, 1256-1267, https://doi.org/10.1128/AEM.02967-13, 2014.

Hill, T. C. J., DeMott, P. J., Tobo, Y., Fröhlich-Nowoisky, J., Moffett, B. F., Franc, G. D., and Kreidenweis, S. M.: Sources of organic ice nucleating particles in soils, Atmos. Chem. Phys., 16, 7195-7211, https://doi.org/10.5194/acp-16-7195-2016, 2016.

Hiranuma, N., Augustin-Bauditz, S., Bingemer, H., Budke, C., Curtius, J., Danielczok, A., Diehl, K., Dreischmeier, K., Ebert, M., Frank, F., Hoffmann, N., Kandler, K., Kiselev, A., Koop, T., Leisner, T., Möhler, O., Nillius, B., Peckhaus, A., Rose, D., Weinbruch, S., Wex, H., Boose, Y., DeMott, P. J., Hader, J. D., Hill, T. C. J., Kanji, Z. A., Kulkarni, G., Levin, E. J. T., McCluskey, C. S., Murakami, M., Murray, B. J., Niedermeier, D., Petters, M. D., O’Sullivan, D., Saito, A., Schill, G. P., Tajiri, T., Tolbert, M. A., Welti, A., Whale, T. F., Wright, T. P., and Yamashita, K.: A comprehensive laboratory study on the immersion freezing behavior of illite NX particles: a comparison of 17 ice nucleation measurement techniques, Atmos. Chem. Phys., 15, 2489-2518, https://doi.org/10.5194/acp-15-2489-2015, 2015.

Huffman, J. A., Prenni, A. J., DeMott, P. J., Pöhlker, C., Mason, R. H., Robinson, N. H., Fröhlich-Nowoisky, J., Tobo, Y., Després, V. R., Garcia, E., Gochis, D. J., Harris, E., Müller-Germann, I., Ruzene, C., Schmer, B., Sinha, B., Day, D. A., Andreae, M. O., Jimenez, J. L., Gallagher, M., Kreidenweis, S. M., Bertram, A. K., and Pöschl, U.: High concentrations of biological aerosol particles and ice nuclei during and after rain, Atmos. Chem. Phys., 13, 6151-6164, https://doi.org/10.5194/acp-13-6151-2013, 2013.

Koop, T., Luo, B., Biermann, U. M., Crutzen, P. J., and Peter, T.: Freezing of $\mathrm{HNO}_{3} / \mathrm{H}_{2} \mathrm{SO}_{4} / \mathrm{H}_{2} \mathrm{O}$ solutions at stratospheric temperatures: Nucleation statistics and experiments, J. Phys. Chem. A, 101, 1117-1133, https://doi.org/10.1021/jp9626531, 1997.

Martin, A. C., Cornwell, G. C., Atwood, S. A., Moore, K. A., Rothfuss, N. E., Taylor, H., DeMott, P. J., Kreidenweis, S. M., Petters, M. D., and Prather, K. A.: Transport of pollution to a remote coastal site during gap flow from California's interior: impacts on aerosol composition, clouds, and radiative balance, Atmos. Chem. Phys., 17, 1491-1509, https://doi.org/10.5194/acp17-1491-2017, 2017.

Mason, R. H., Chou, C., McCluskey, C. S., Levin, E. J. T., Schiller, C. L., Hill, T. C. J., Huffman, J. A., DeMott, P. J., and Bertram, A. K.: The micro-orifice uniform deposit impactordroplet freezing technique (MOUDI-DFT) for measuring concentrations of ice nucleating particles as a function of size: improvements and initial validation, Atmos. Meas. Tech., 8, 24492462, https://doi.org/10.5194/amt-8-2449-2015, 2015.

Mason, R. H., Si, M., Chou, C., Irish, V. E., Dickie, R., Elizondo, P., Wong, R., Brintnell, M., Elsasser, M., Lassar, W. M., Pierce, K. M., Leaitch, W. R., MacDonald, A. M., Platt, A., ToomSauntry, D., Sarda-Estève, R., Schiller, C. L., Suski, K. J., Hill, T. C. J., Abbatt, J. P. D., Huffman, J. A., DeMott, P. J., and Bertram, A. K.: Size-resolved measurements of ice-nucleating particles at six locations in North America and one in Europe, Atmos. Chem. Phys., 16, 1637-1651, https://doi.org/10.5194/acp16-1637-2016, 2016.

McCluskey, C. S., DeMott, P. J., Prenni, A. J., Levin, E. J., McMeeking, G. R., Sullivan, A. P., Hill, T. C., Nakao, S., Car- rico, C. M., and Kreidenweis, S. M.: Characteristics of atmospheric ice nucleating particles associated with biomass burning in the US: Prescribed burns and wildfires, J. Geophys. Res., 119, 10458-10470, 2014.

Murray, B. J, O’Sullivan, D., Atkinson, J. D., and Webb, M. E.: Ice nucleation by particles immersed in supercooled cloud droplets, Chem. Soc. Rev., 41, 6519-6554, 2012.

Ortega, J., Turnipseed, A., Guenther, A. B., Karl, T. G., Day, D. A., Gochis, D., Huffman, J. A., Prenni, A. J., Levin, E. J. T., Kreidenweis, S. M., DeMott, P. J., Tobo, Y., Patton, E. G., Hodzic, A., Cui, Y. Y., Harley, P. C., Hornbrook, R. S., Apel, E. C., Monson, R. K., Eller, A. S. D., Greenberg, J. P., Barth, M. C., Campuzano-Jost, P., Palm, B. B., Jimenez, J. L., Aiken, A. C., Dubey, M. K., Geron, C., Offenberg, J., Ryan, M. G., Fornwalt, P. J., Pryor, S. C., Keutsch, F. N., DiGangi, J. P., Chan, A. W. H., Goldstein, A. H., Wolfe, G. M., Kim, S., Kaser, L., Schnitzhofer, R., Hansel, A., Cantrell, C. A., Mauldin, R. L., and Smith, J. N.: Overview of the Manitou Experimental Forest Observatory: site description and selected science results from 2008 to 2013, Atmos. Chem. Phys., 14, 6345-6367, https://doi.org/10.5194/acp14-6345-2014, 2014.

O'Sullivan, D., Murray, B. J., Ross, J. F., and Webb, M. E.: The adsorption of fungal ice-nucleating proteins on mineral dusts: a terrestrial reservoir of atmospheric ice-nucleating particles, Atmos. Chem. Phys., 16, 7879-7887, https://doi.org/10.5194/acp16-7879-2016, 2016.

Petters, M. D. and Wright, T. P.: Revisiting ice nucleation from precipitation samples, Geophys. Res. Lett., 42, 8758-8766, 2015.

Petters, M. D., Parsons, M. T., Prenni, A. J., DeMott, P. J., Kreidenweis, S. M., Carrico, C. M., Sullivan, A. P., McMeeking, G. R., Levin, E., Wold, C. E., Collett, J. L. J., and Moosmüller, H.: Ice nuclei emissions from biomass burning, J. Geophys. Res., 114, D07209, https://doi.org/10.1029/2008JD011532, 2009.

Prenni, A. J., Tobo, Y., Garcia, E., DeMott, P. J., McCluskey, C., Kreidenweis, S. M., Prenni, J., Huffman, A., Pöschl, U., and Pöhlker, C.: The impact of rain on ice nuclei populations, Geophys. Res. Lett., 40, 227-231, https://doi.org/10.1029/2012GL053953, 2013.

Prenni A. J., DeMott, P. J., Rogers, D. C., Kreidenweis, S. M., McFarquhar, G. M., Zhang, G., and Poellot, M. R.: Ice nuclei characteristics from M-PACE and their relation to ice formation in clouds, Tellus B, 61, 436-448, 2009.

Ralph, F. M., Prather, K. A., Cayan, D., Spackman, J. R., DeMott, P. J., Dettinger, M., Fairall, C., Leung, R., Rosenfeld, D., Rutledge, S., Waliser, D., White, A. B., Cordeira, J., Martin, A., Helly, J., and Intrieri, J.: CalWater Field Studies Designed to Quantify the Roles of Atmospheric Rivers and Aerosols in Modulating U.S. West Coast Precipitation in a Changing Climate, B. Am. Meteorol. Soc., 97, 1209-1228, https://doi.org/10.1175/BAMS-D-14$00043.1,2016$.

Schill, G. P., Jathar, S. H., Krodos, J. K., Levin, E. J. T., Galang, A. M., Friedman, B., Farmer, D. K., Pierce, J. R., Kreidenweis, S. M., and DeMott, P. J.: Ice nucleating particle emissions from photo-chemically-aged diesel and biodiesel exhaust, Geophys. Res. Lett., 43, 5524-5531, https://doi.org/10.1002/2016GL069529, 2016.

Schrod, J., Danielczok, A., Weber, D., Ebert, M., Thomson, E. S., and Bingemer, H. G.: Re-evaluating the Frankfurt isothermal 
static diffusion chamber for ice nucleation, Atmos. Meas. Tech., 9, 1313-1324, https://doi.org/10.5194/amt-9-1313-2016, 2016.

Schrod, J., Weber, D., Drücke, J., Keleshis, C., Pikridas, M., Ebert, M., Cvetkovic, B., Nickovic, S., Marinou, E., Baars, H., Ansmann, A., Vrekoussis, M., Mihalopoulos, N., Sciare, J., Curtius, J., and Bingemer, H. G.: Ice nucleating particles over the Eastern Mediterranean measured by unmanned aircraft systems, Atmos. Chem. Phys., 17, 4817-4835, https://doi.org/10.5194/acp17-4817-2017, 2017.

Spurny K. R. and Lodge Jr., J. P.: Collection efficiency tables for membrane filters usedin the sampling and analysis of aerosols and hydrosols, CAR Technical Note, National Center for Atmospheric Research, Boulder, CO, NCAR-TN/STR-77, Vol. I, 1972.

Stopelli, E., Conen, F., Morris, C. E., Herrmann, E., Bukowiecki, N., and Alewell, C.: Ice nucleation active particles are efficiently removed by precipitating clouds, Sci. Rep.-UK, 5, 16433, https://doi.org/10.1038/srep16433, 2015.

Tobo, Y.: An improved approach for measuring immersion freezing in large droplets over a wide temperature range, Sci. Rep.-UK, 6, 32930, https://doi.org/10.1038/srep32930, 2016.

Tobo, Y., Prenni, A. J., DeMott, P. J., Huffman, J. A., McCluskey, C. S., Tian, G., Pöhlker, C., Pöschl, U., and Kreidenweis, S. M.: Biological aerosol particles as a key determinant of ice nuclei populations in a forest ecosystem. J. Geophys. Res.-Atmos., 118, 10100-10110, https://doi.org/10.1002/jgrd.50801, 2013.

Vali, G.: Quantitative evaluation of experimental results on the heterogeneous freezing nucleation of supercooled liquids, J. Atmos. Sci., 28, 402-409, 1971.

Vali, G.: Interpretation of freezing nucleation experiments: singular and stochastic; sites and surfaces, Atmos. Chem. Phys., 14, 5271-5294, https://doi.org/10.5194/acp-14-5271-2014, 2014.
Vali, G., DeMott, P. J., Möhler, O., and Whale, T. F.: Technical Note: A proposal for ice nucleation terminology, Atmos. Chem. Phys., 15, 10263-10270, https://doi.org/10.5194/acp-15-102632015, 2015.

Welti, A., Lüönd, F., Kanji, Z. A., Stetzer, O., and Lohmann, U.: Time dependence of immersion freezing: an experimental study on size selected kaolinite particles, Atmos. Chem. Phys., 12, 9893-9907, https://doi.org/10.5194/acp-12-9893-2012, 2012.

Wex, H., Augustin-Bauditz, S., Boose, Y., Budke, C., Curtius, J., Diehl, K., Dreyer, A., Frank, F., Hartmann, S., Hiranuma, N., Jantsch, E., Kanji, Z. A., Kiselev, A., Koop, T., Möhler, O., Niedermeier, D., Nillius, B., Rösch, M., Rose, D., Schmidt, C., Steinke, I., and Stratmann, F.: Intercomparing different devices for the investigation of ice nucleating particles using Snomax ${ }^{\circledR}$ as test substance, Atmos. Chem. Phys., 15, 14631485, https://doi.org/10.5194/acp-15-1463-2015, 2015.

Willeke, K., Lin, X., and Grinshpun, S. A.: Improved Aerosol Collection by Combined Impaction and Centrifugal Motion, Aerosol Sci. Techno., 28, 439-456, https://doi.org/10.1080/02786829808965536, 1998.

Wright, T. P. and Petters, M. D.: The role of time in heterogeneous freezing nucleation, J. Geophys. Res.-Atmos., 118, 3731-3743, https://doi.org/10.1002/jgrd.50365, 2013.

Wright, T. P., Petters, M. D., Hader, J. D., Morton, T., and Holder, A. L.: Minimal cooling rate dependence of ice nuclei activity in the immersion mode, J. Geophys. Res.-Atmos., 118, 10535-10 543, https://doi.org/10.1002/jgrd.50810, 2013. 